Check for updates

Cite this: RSC Adv., 2020, 10, 44159

Received 10th October 2020

Accepted 23rd November 2020

DOI: 10.1039/d0ra08647a

rsc.li/rsc-advances

\section{The influence of the polymerization approach on the catalytic performance of novel porous poly (ionic liquid)s for green synthesis of pharmaceutical spiro-4-thiazolidinones $\uparrow$}

\author{
Zahra Elyasi, ${ }^{a}$ Javad Safaei Ghomi, (D) *ab Gholam Reza Najafi ${ }^{a}$ \\ and Mohammad Reza Zand Monfared ${ }^{a}$
}

Although poly (ionic liquids) (PILs) have attracted great research interest owing to their various applications, the performance of nanoporous PILs has been rarely developed in the catalysis field. To this end, a micromesoporous PIL with acid-base bifunctional active sites was designed and fabricated by two different polymerization protocols including hydrothermal and classical precipitation polymerization in this paper. Based on our observations, hydrothermal conditions (high temperature and pressure) enabled the proposed sonocatalyst to possess a great porous structure with a high specific surface area $\left(S_{\text {BET: }} 315 \mathrm{~m}^{2}\right.$ $\mathrm{g}^{-1}$ ) and thermal stability (around $450{ }^{\circ} \mathrm{C}$ for $45 \%$ weight loss) through strengthening cross-linking. In a comparative study, the preferred nanoporous PIL was selected and utilized as the sonocatalyst in a multicomponent reaction of isatins, primary amines, and thioglycolic acid. In the following, a variety of new and known pharmaceutical spiro-4-thiazolidinone derivatives were synthesized at room temperature and obtained excellent yields (>90\%) within short reaction times (4-12 min) owing to the substantial synergistic effect between ultrasound irradiation and magnetically separable catalyst.

\section{Introduction}

The indole scaffold is known as one of the most important structures in heterocyclic chemistry owing to its widespread pharmacological and bioavailability applications, such as antiinflammatory, antimicrobial, anti-hypertensive, anti-cancer, and anti-diabetic (Fig. 1). ${ }^{1-6}$ In addition, 4-thiazolidinone derivatives are privileged heterocyclic compounds with significant potential pharmaceutical performance, especially in the design of various anticancer agents. ${ }^{7-9}$ Therefore, several methods have been investigated for the synthesis of spiro [indole-thiazolidinones] compounds by reacting isatins with mercaptoacetic acid and amines under various conditions. ${ }^{10-13}$ However, many reported methods suffer from drawbacks, such as longer reaction times, high reaction temperature, use of flammable solvents, tedious workup, lower yields of the products, and expensive catalysts. Therefore, introducing an environmentally benign and straightforward synthetic strategy for the preparation of spiro[indolethiazolidinones] is an essential goal.

aDepartment of Chemistry, Qom Branch, Islamic Azad University, Post Box: 37491-13191, Qom, I. R. Iran. E-mail: safaei@kashanu.ac.ir; Fax: +98 31 55552935; Tel: +983155912385

${ }^{b}$ Department of Organic Chemistry, Faculty of Chemistry, University of Kashan, Iran $\dagger$ Electronic supplementary information (ESI) available. See DOI: $10.1039 /$ d0ra08647a
Radical-initiated polymerization processes, including dispersion, suspension, and emulsion polymerization, are traditional protocols for the construction of synthetic polymers owing to the polymer materials separation and ease of heat removal. ${ }^{14-16}$

In these heterogeneous polymerizations, polymeric surfactants or emulsifiers are used to stabilize the latex particles or monomer droplets. In recent decades, the precipitation polymerization has developed and in which any added surfactant or stabilizer is absent compared to traditional polymerization protocols. ${ }^{17}$ However, a low monomer concentration $(<5 \mathrm{wt} \%)$ leads to heavy consumption of solvent and low relative yield $(<50 \%)$. Recently, several new methods have been investigated to overcome these limitations, including solvothermal precipitation polymerization, redox-initiated precipitation

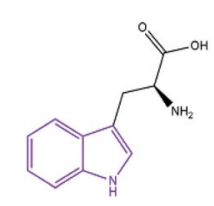

Tryptophan

Fig. 1 Indole scaffold in pharmacologically and biologically compounds 
polymerization, and photoinitiated precipitation polymerization. ${ }^{18-22}$ Ionic liquids bearing polymerizable groups could be polymerized under different conditions to form a new class of polyelectrolytes, which are named poly (ionic liquids) (PILs). ${ }^{23,24}$ They are able to provide the properties of both the ionic liquids and conventional polymers. Therefore, they opened up a wide window to various range of applications, such as catalysts, surface active materials, fuel cells, and membranes. ${ }^{25-29}$ Recently, the interest in their applications and synthesis kept growing, particularly those made from $N$-vinyl imidazoliumbased monomers. ${ }^{30}$ Typically, imidazolium-based PILs are great metal-free catalysts due to their remarkable properties like good stability, tunable structure, and low vapor pressure. However, many PILs catalysts, reported in the literature, have low active site concentrations and poor porosities. ${ }^{31,32}$ Therefore, there is a challenge to synthesize porous PILs with a large amount of porosity and high specific surface areas. On the other hand, the stability of the porous materials is an important prerequisite for their various applications. The broad application rang of zeolites is attributed to their great hydrothermal and thermal stabilities. ${ }^{33,34}$ Although Metal Organic Frameworks (MOFs) have uniform pore sizes (due to their crystallinity) compared to zeolites, their applications are limited by their sensitivity to moisture, particularly in the presence of base or acid chemicals. ${ }^{35,36}$ While, porous ionic polymers (PIPs) containing chemically stable covalent bonds exhibited high hydrothermal, chemical, and thermal stabilities. Therefore, PIPs could be selected as efficient heterogeneous catalysts owing to their excellent stabilities which can facilitate the reuse and recovery of catalysts. ${ }^{37,38}$ Mesoporous PILs (as the main branch of the PIPs category) could be fabricated to possess intrinsic networks with exchangeable anions and porous structure among proper polymerization processes ${ }^{39,40}$ Immobilization of PILs onto the magnetic supports is another practical procedure for improving the reusability and stability. ${ }^{41}$ In continuation of our investigations about introducing synthetic methodologies in the presence of efficient nanocatalyst, ${ }^{42-46}$ a new type of porous poly ionic liquid has been fabricated under two comparative polymerization methods. We designed and synthesized a new hypercrosslinked PIL immobilized on vinyl functionalized $\mathrm{Co}_{3} \mathrm{O}_{4}$ nanoparticles as a high effective catalyst for green preparation of spiro[indole-thiazolidinone] derivatives.

\section{Results and discussion}

Proving appropriate reaction conditions for NPs' surfaces is known as one of their most important modification. Having high magnetic behavior can also increase their importance due to the fact that they are generally absorbed to the magnet along with the magnetically stirring. In order to overcome this challenge, $\mathrm{Co}_{3} \mathrm{O}_{4}$ NPs were selected as the magnetic core instead of $\mathrm{Fe}_{3} \mathrm{O}_{4}$ NPs. In addition, the surface of MNPs has been modified by MPS before the polymerization process which caused grafting of polymeric networks on MNPs by covalent bonding. On the other hand, two different methods were applied to study the effect of polymerization protocol on the morphology and efficiency of the prepared catalyst. Based on the observations, prepared porous PIL is highly sensitive to the polymerization process. The catalyst obtained from the hydrothermal precipitation polymerization is in the class of nanoscale materials with high porosity structure. The high specific surface area in combination with porous morphology, and thermal stability supply catalysis application. Finally, the preferred catalyst was used to facilitate the one-pot synthesis of spiro-2,3disubstituted-4-thiazolidinones in an aqueous system under ultrasound condition.

\subsection{Structural and textural analysis of $\mathrm{Co}_{3} \mathrm{O}_{4} @$ @crosslinked $\mathrm{p}$ [AVIM]Br nanocatalyst}

In order to obtain more accurate information, the FT-IR analysis of the $\mathrm{Co}_{3} \mathrm{O}_{4}$ NPs, $\mathrm{Co}_{3} \mathrm{O}_{4} @ \mathrm{MPS},[\mathrm{AVIM}] \mathrm{Br}$ monomers, and $\mathrm{Co}_{3} \mathrm{O}_{4}$ @crosslinked p[AVIM]Br was performed. As shown in (Fig. 2a), the strong peaks at 655 and $575 \mathrm{~cm}^{-1}$ are attributed to the characteristic peaks of spinel $\mathrm{Co}_{3} \mathrm{O}_{4}$. The peaks at $655 \mathrm{~cm}^{-1}$ belong to the stretching vibration of metal-O in which $\mathrm{M}$ is $\mathrm{Co}^{2+}$. While the absorption band at $575 \mathrm{~cm}^{-1}$ can be attributed to the metal-O in which $\mathrm{M}$ is $\mathrm{Co}^{3+}$. Coating of MPS onto the $\mathrm{Co}_{3} \mathrm{O}_{4}$ NPs surface is also confirmed by peaks at 1100,1540 , and $1740 \mathrm{~cm}^{-1}$ which respectively belong to stretching vibrations of $\mathrm{Si}-\mathrm{O}, \mathrm{C}=\mathrm{C}$, and steric $\mathrm{C}=\mathrm{O}$ (Fig. 2b). As it can be seen in (Fig. 2c), the stretching and bending vibration of the vinyl group

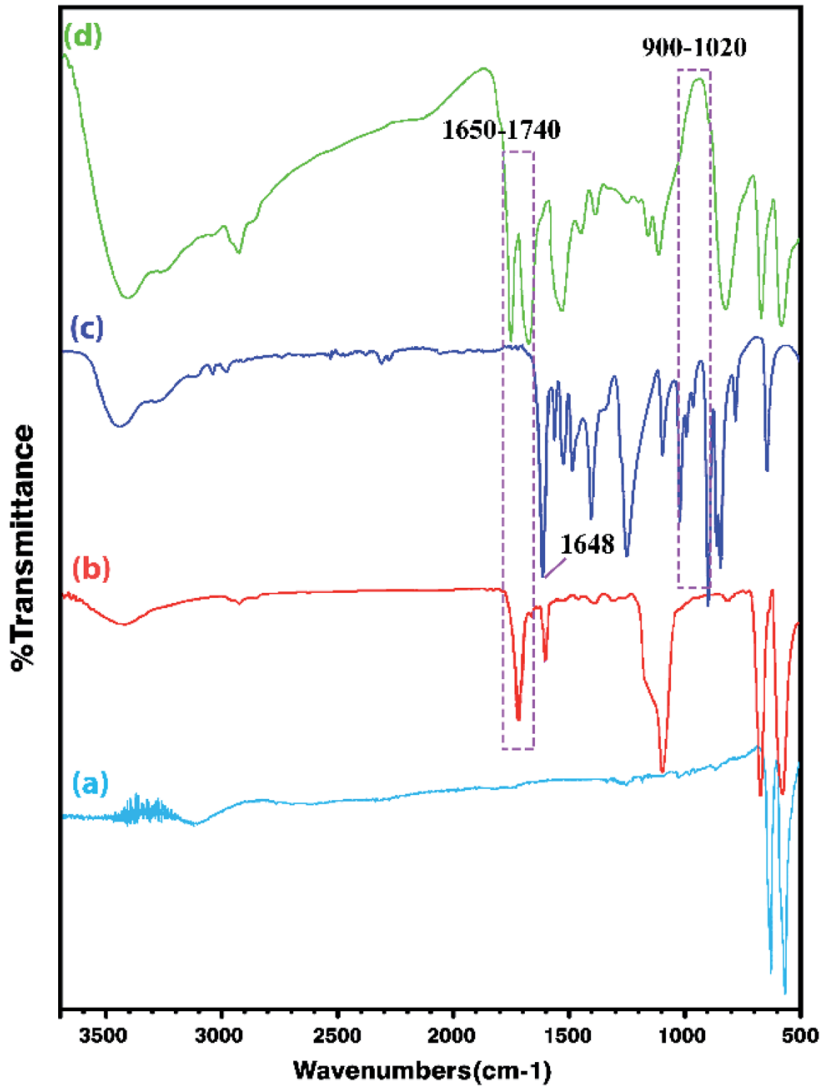

Fig. 2 The FT-IR spectra of (a) $\mathrm{Co}_{3} \mathrm{O}_{4}$, (b) $\mathrm{Co}_{3} \mathrm{O}_{4}$ @MPS, (c) ionic monomer, and (d) crosslinked $\mathrm{Co}_{3} \mathrm{O}_{4}$ @ p $[\mathrm{AVIM}] \mathrm{Br}$. 


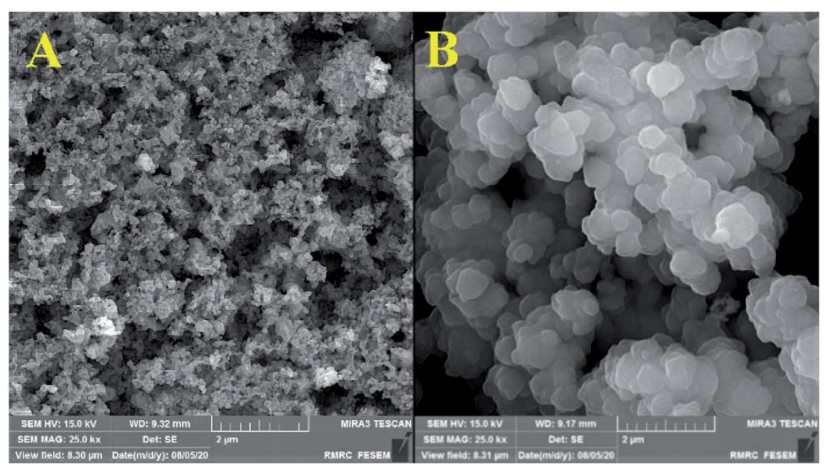

Fig. 3 Comparative FESEM images of $\mathrm{CO}_{3} \mathrm{O}_{4} \mathrm{Qp}[\mathrm{AVIM}] \mathrm{Br}$, under (A) hydrothermal treated, and (B) classical precipitation polymerization in $2 \mu \mathrm{m}$.

of the imidazole ring have respectively appeared at $1648 \mathrm{~cm}^{-1}$ and $932-1020 \mathrm{~cm}^{-1}$. These mentioned peaks are not seen in the $\mathrm{Co}_{3} \mathrm{O}_{4}$ @crosslinked p[AVIM]Br spectrum confirming polymerization (Fig. 2d).

Moreover, the characteristic peaks of N-C-N at $660 \mathrm{~cm}^{-1}$ and $1228 \mathrm{~cm}^{-1}$ are retained after the polymerization process in the spectrum as well. The imidazole $\mathrm{H}-\mathrm{C}-\mathrm{C} \& \mathrm{H}-\mathrm{C}-\mathrm{N}$ bending vibration also appears at $1168 \mathrm{~cm}^{-1}$ while the peak at $824 \mathrm{~cm}^{-1}$ corresponds to the in-plane imidazole ring bending. ${ }^{47}$ Notably, these mentioned peaks were observed in both IL monomer and PILs spectra. The doublet around $2850-3000 \mathrm{~cm}^{-1}$ corresponds to symmetric $\nu_{\mathrm{s}}\left(\mathrm{CH}_{2}\right)$ and asymmetric $\nu_{\mathrm{as}}\left(\mathrm{CH}_{2}\right)$ of the IL monomers. The broad peak at about $3300 \mathrm{~cm}^{-1}$ to $3530 \mathrm{~cm}^{-1}$ also belongs to the quaternary nitrogen of imidazolium with bromide. ${ }^{47}$ As shown in Fig. 2d, the observed strong peak at $1670 \mathrm{~cm}^{-1}$ is attributed to the characteristic peak of carbonyl groups of $N, N^{\prime}$-methylenebisacrylamide.

Fig. 3 and 4 show the FE-SEM images for porous PILs synthesized by hydrothermal precipitation and classical precipitation polymerization process. As it can be seen, an

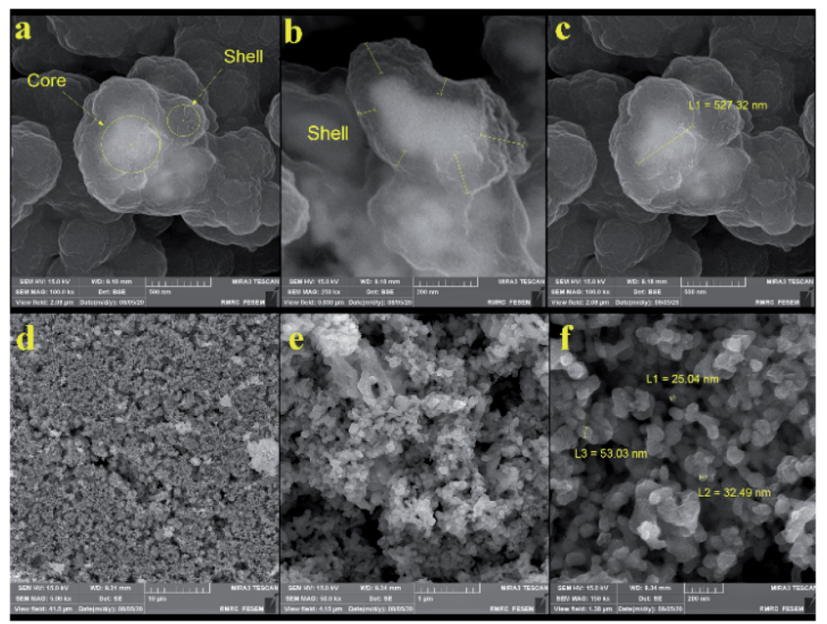

Fig. 4 FE-SEM images of sonocatalyst obtained through (a-c) classical precipitation, and $(d-f)$ hydrothermal precipitation polymerization.
Table 1 Textural property of the $\mathrm{CO}_{3} \mathrm{O}_{4}$ (acrosslinked p[AVIM]Br

\begin{tabular}{llll}
\hline Entry PIL & $\begin{array}{l}S_{\mathrm{BET}}{ }^{a} \\
\left(\mathrm{~m}^{2} \mathrm{~g}^{-1}\right)\end{array}$ & $\begin{array}{l}V_{\mathrm{P}}{ }^{b} \\
\left(\mathrm{~cm}^{3} \mathrm{~g}^{-1}\right)\end{array}$ & $\begin{array}{l}D_{\mathrm{av}}{ }^{c} \\
(\mathrm{~nm})\end{array}$ \\
\hline $1 \quad \begin{array}{l}\text { Hydrothermal } \\
\text { precipitation polymerization } \\
2\end{array}$ & 315 & 0.29 & 3.1 \\
$\quad \begin{array}{l}\text { Classical precipitation } \\
\text { polymerization }\end{array}$ & 110 & 0.37 & 10.7 \\
${ }^{a}$ BET surface area. ${ }^{b}$ Total pore volume. ${ }^{c}$ Average pore size.
\end{tabular}

obvious porous and crosslinked polymeric network was formed in both methods. As shown in Fig. 3, autoclaving temperature and pressure have a significant effect on the morphology in contrast. Based on the observations, hydrothermal conditions (high temperature and pressure) enabled the PIL to possess great porous structure through strengthening crosslinking.

Actually, the diameter of particles increased as the temperature decreased. Increasing the temperature from $80{ }^{\circ} \mathrm{C}$ (reflux) to $150{ }^{\circ} \mathrm{C}$ (autoclave) leads to the formation of a crosslinked magnetic core and polymeric shell structures with $25-50 \mathrm{~nm}$ (Fig. 4f). While classical precipitation polymerization provides the magnetic core diameter of $\sim 527 \mathrm{~nm}$ (Fig. 4c). Notably, the growth of particles is occurred due to their paramagnetic behavior and lack of enough energy force (temperature and pressure) for good dispersion. Moreover, the uniform porous structure of the $\mathrm{Co}_{3} \mathrm{O}_{4}$ @crosslinked p[AVIM]Br was determined through Fig. 4d.

The porous structure is a key characteristics factor in the world of catalysts which affects their chemical and physical properties. As shown in FE-SEM images, the type of polymerization process extremely changed their morphology and structure which could have significant effects on the surface properties of the catalyst.

The $\mathrm{N}_{2}$ isotherm of the hydrothermal sample illustrated the type IV behavior with an obvious $\mathrm{H} 2$ type hysteresis loop in the pressure ranges from 0.65 to 1.00 , implying the presence of

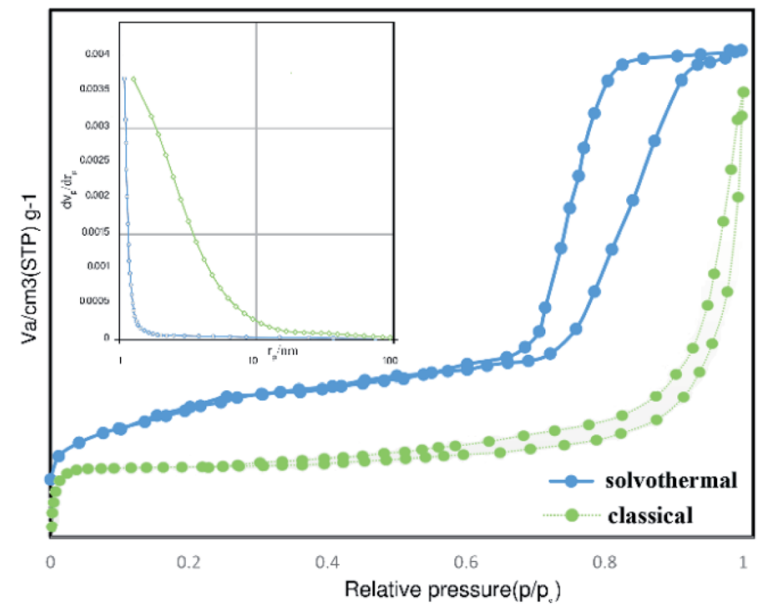

Fig. 5 Pore size distributions and nitrogen adsorption desorption isotherms of $\mathrm{CO}_{3} \mathrm{O}_{4} @ \mathrm{ap}[\mathrm{AVIM}] \mathrm{Br}$ catalyst. 
microporous and mesoporous. Moreover, the classical sample of $\mathrm{Co}_{3} \mathrm{O}_{4}$ @crosslinked p[VIM]Br showed the type IV isotherm with a distinctive $\mathrm{H} 1$ type hysteresis loop in the relative pressure ranges from 0.4 to 1.00 , confirming the characteristic mesoporous structure. The specific surface area of prepared PIL through classical precipitation polymerization $\left(\sim 110.0 \mathrm{~m}^{2} \mathrm{~g}^{-1}\right)$ was less than one-third compared to the one that was obtained through hydrothermal precipitation polymerization $\left(\sim 315.0 \mathrm{~m}^{2}\right.$ $\mathrm{g}^{-1}$ ). Moreover, their pore size distributions and total pore volumes were quite different as demonstrated in Table 1. As it can be seen in Fig. 5, the absence of a step change in the pore size distribution of samples revealed that the distribution is non-zero $<60 \mathrm{~nm}$. Therefore, there are many pores in the network in which $\mathrm{N}_{2}$ gas is not condensed at the highest pressure. For the PIL obtained through classical precipitation polymerization, most pores were over $10 \mathrm{~nm}$ with a wide range distribution. Hydrothermal condition provided a higher degree of cross linking that led to more porous structure and smaller pore size distribution.

Thus, fabricated $\mathrm{Co}_{3} \mathrm{O}_{4}$ @crosslinked p[AVIM]Br through hydrothermal polymerization resulted in a much higher proper pores structure and specific surface area which not only stem from the co-existence of random micro and mesoporous but also can greatly enhance their catalytic activity in organic synthesis.

Thermo Gravimetric Analysis (TGA) of the $\mathrm{Co}_{3} \mathrm{O}_{4} @$ crosslinked $\mathrm{p}[\mathrm{AVIM}] \mathrm{Br}$ was separately investigated for $\mathrm{Co}_{3^{-}}$ $\mathrm{O}_{4}$ @crosslinked $\mathrm{p}$ [AVIM]Br catalyst under hydrothermal precipitation and classical precipitation polymerization methods to determine the effect of polymerization approach on thermal stability. The initial weight loss at low temperature $\left(<200{ }^{\circ} \mathrm{C}\right)$ is attributed to the evaporation of physically adsorbed water owing to the hydrophilic nature of ionic liquid units (Fig. 6). The onset thermal degradation temperature $\left(T_{\mathrm{d}}\right)$ value for $\mathrm{Co}_{3} \mathrm{O}_{4} @$ @crosslinked p[AVIM]Br was about $420{ }^{\circ} \mathrm{C}$ under hydrothermal condition. The hydrothermal treated $\mathrm{Co}_{3} \mathrm{O}_{4} @ \mathrm{p}$ [AVIM] Br showed a drastic weight loss of $45 \%$ between the temperature $420-500{ }^{\circ} \mathrm{C}$ which can be due to the decomposition of the major bond between cross-linking and ionic monomers. $\mathrm{Co}_{3} \mathrm{O}_{4} @ \mathrm{p}[\mathrm{AVIM}] \mathrm{Br}$ shows a fast weight loss up to $380{ }^{\circ} \mathrm{C}(70 \%$

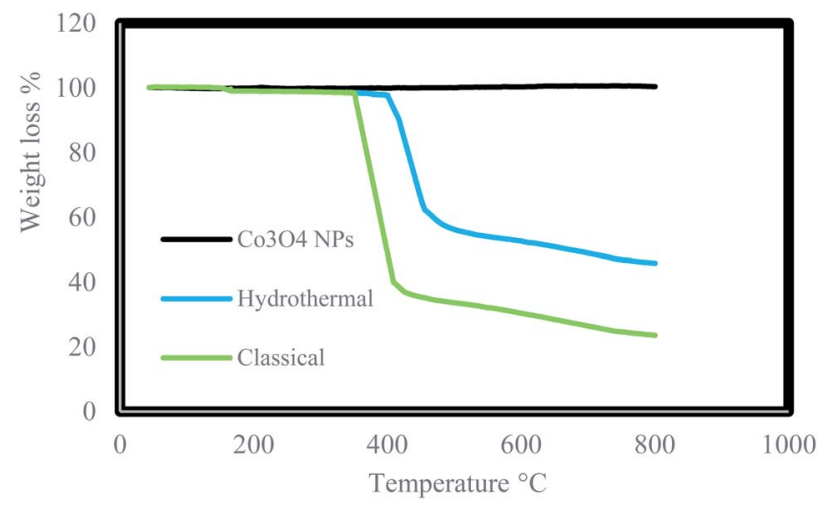

Fig. 6 TGA analysis of $\mathrm{CO}_{3} \mathrm{O}_{4} \mathrm{NPS}$, prepared $\mathrm{CO}_{3} \mathrm{O}_{4}$ @p [AVIM]Br under hydrothermal and classical precipitation methods.

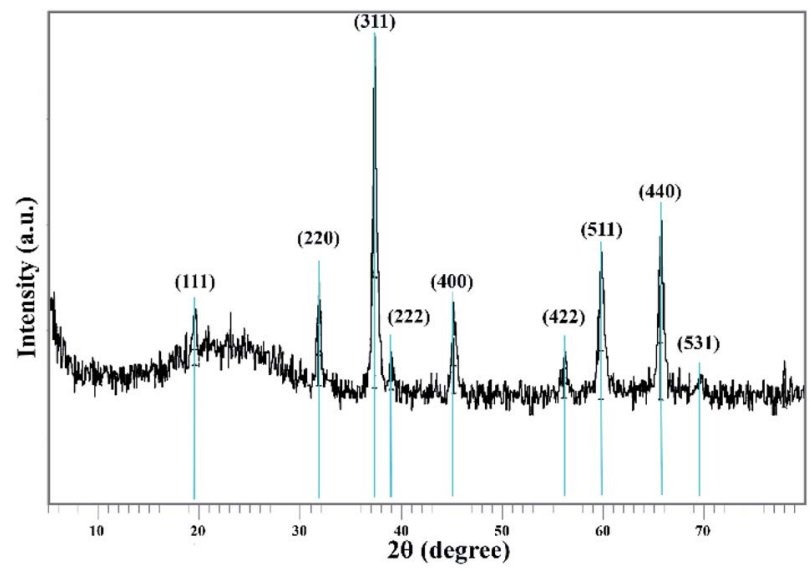

Fig. 7 XRD pattern of sonocatalyst.

weight loss) indicating the rapid decomposition of structure through classical method. It was assumed that a difference in the network forces (different degree of crosslinking) or morphology may explain the difference obtained in the thermal stability of samples. Thus, fabricated $\mathrm{Co}_{3} \mathrm{O}_{4}$ @crosslinked $\mathrm{p}$ [AVIM] $\mathrm{Br}$ through hydrothermal polymerization illustrated more thermal stability.

The $\mathrm{Co}_{3} \mathrm{O}_{4} @$ @crosslinked p[AVIM]Br structure was investigated by the measurements of powder X-Ray Diffraction (XRD) (Fig. 7). The XRD pattern of the proposed catalyst clearly illustrated 9 reflection peaks at $2 \theta=19.45,31.701,37.263,38.97$, 45.174, 56.11, 59.773, 65.629, and 69.41. All of the appeared peaks were consistent with the peak positions of face-centered cubic $\mathrm{Co}_{3} \mathrm{O}_{4}$ (fcc, $F d 3 m$, JCPDS card no. 01-080-1533). A broad peak around $20^{\circ}$ belongs to the amorphous silica around the $\mathrm{Co}_{3} \mathrm{O}_{4}$ core. These experimental results showed that the modifications did not cause a phase change in the $\mathrm{Co}_{3} \mathrm{O}_{4}$ particles.

Energy-Dispersive X-ray spectroscopy (EDX) analysis and elemental mapping images of $\mathrm{Co}_{3} \mathrm{O}_{4}$ @crosslinked p[AVIM]Br are presented in (Fig. S2 $\dagger$ ). In the EDX spectrum of the prepared $\mathrm{PIL}$, expected elements (C, O, N, Co, Si, Br) have appeared in their regions. Elemental mapping results clearly determined that all the related elements, from PILs, are well distributed throughout the $\mathrm{Co}_{3} \mathrm{O}_{4}$ @crosslinked p[AVIM]Br slices.

Vibrating sample magnetometer was investigated to confirm the magnetic behavior of the catalyst at room temperature. According to the linear magnetization diagram (Fig. S3†), the prepared catalyst has paramagnetic behavior. The magnetization was $0.48 \mathrm{emu}^{-1}$ at $14000 \mathrm{Oe}$. It is worth mentioning that the final catalyst magnetization is enough and therefore it can be separated from the reaction mixture using an external magnet.

\subsection{Measurement of catalytic activity of MNP@crosslinked $\mathrm{p}[\mathrm{AVIM}] \mathrm{Br}$ through the one-pot synthesis of spiro[indoline- 3,2'-thiazolidinones]}

In order to screen the catalytic activity of the prepared $\mathrm{Co}_{3}$ $\mathrm{O}_{4}$ @crosslinked p[AVIM]Br, a one-pot multicomponent reaction between isatin, aniline, and thioglycolic acid was first 
Table 2 Screening of different condition for the synthesis of desired product $4 a^{a}$

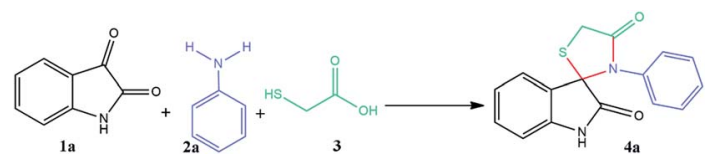

\begin{tabular}{|c|c|c|c|c|c|}
\hline Entry & Solvent & Catalyst & Condition & Time (min) & Yield $\%^{b}$ \\
\hline 1 & $\mathrm{H}_{2} \mathrm{O}$ & - & US & 20 & 18 \\
\hline 2 & $\mathrm{H}_{2} \mathrm{O}$ & $\mathrm{Co}_{3} \mathrm{O}_{4}$ NPs $(10 \mathrm{~mol} \%)$ & US & 8 & 48 \\
\hline 3 & $\mathrm{H}_{2} \mathrm{O}$ & $(10 \mathrm{~mol} \%)$ & US & 6 & 94 \\
\hline 4 & $\mathrm{H}_{2} \mathrm{O}$ & Classical- $\mathrm{Co}_{3} \mathrm{O}_{4} @ \mathrm{p}[\mathrm{AVIM}] \mathrm{Br}$ & US & 15 & 88 \\
\hline 5 & $\mathrm{H}_{2} \mathrm{O}$ & $(5 \mathrm{~mol} \%)$ & US & 5 & 80 \\
\hline 6 & $\mathrm{H}_{2} \mathrm{O}$ & $(15 \mathrm{~mol} \%)$ & US & 5 & 93 \\
\hline 7 & $\mathrm{H}_{2} \mathrm{O}$ & $(10 \mathrm{~mol} \%)$ & $\Delta$ & 90 & 92 \\
\hline 8 & EtOH & $(10 \mathrm{~mol} \%)$ & US & 10 & 90 \\
\hline 9 & $\mathrm{EtOH} / \mathrm{H}_{2} \mathrm{O}$ & $(10 \mathrm{~mol} \%)$ & US & 10 & 92 \\
\hline 10 & $\mathrm{CH}_{3} \mathrm{CN}$ & $(10 \mathrm{~mol} \%)$ & US & 10 & 89 \\
\hline 11 & $\mathrm{CH}_{2} \mathrm{Cl}_{2}$ & $(10 \mathrm{~mol} \%)$ & US & 15 & 85 \\
\hline 12 & THF & (10 mol\%) & US & 30 & 80 \\
\hline 13 & Toluene & $(10 \mathrm{~mol} \%)$ & US & 30 & 60 \\
\hline 14 & $\mathrm{MeOH}$ & $(10 \mathrm{~mol} \%)$ & US & 10 & 91 \\
\hline 15 & DMF & (10 mol\%) & US & 20 & 62 \\
\hline 16 & Dioxane & $(10 \mathrm{~mol} \%)$ & US & 20 & 55 \\
\hline
\end{tabular}

${ }^{a}$ Reaction conditions: isatin $(1 \mathrm{mmol})$, aniline $(1 \mathrm{mmol})$ and thioglycolic acid $(1 \mathrm{mmol})$ in the presence of hydrothermal treated MNP@crosslinked $\mathrm{p}[\mathrm{AVIM}] \mathrm{Br} .{ }^{b}$ Isolated yield.

chosen as a model reaction. The reaction was optimized under various conditions and the experimental results are summarized in Table 2. Initially, the model reaction was carried out in $\mathrm{H}_{2} \mathrm{O}$ as the greenest solvent in the presence of different catalysis. Based on the data, the reaction, which was done without any catalyst, resulted in trace yield (Table 2, entry 1 ). According to the empirical results, although the $\mathrm{Co}_{3} \mathrm{O}_{4}$ @crosslinked $\mathrm{p}$ [AVIM] Br obtained through classical precipitation polymerization was efficient (Table 2 , entry 4 ), the hydrothermal $\mathrm{Co}_{3}$ $\mathrm{O}_{4} @$ @crosslinked $\mathrm{p}[\mathrm{AVIM}] \mathrm{Br}$ was the best one (Table 2, entry 3). The significant effect of hydrothermal precipitation polymerization on the textural and structural properties (surface area, porosity, particle size, thermal stability) led to greater efficiency of $\mathrm{Co}_{3} \mathrm{O}_{4} @$ @crosslinked p[AVIM]Br. To adjust the amount of catalyst, different experiments were conducted. Accordingly, by increasing the amount of sonocatalyst from 5 to $10 \mathrm{~mol} \%$, the yield was increased from 80 to $94 \%$ while more nanocatalyst amount (15 mol\%) did not improve the reaction yield (Table 2, entry 6). In order to determine the effect of ultrasonic agitation, the reaction was carried out in $\mathrm{H}_{2} \mathrm{O}$ as solvent by mechanical stirring under silent condition (Table 2, entry 7 ). The obtained result showed that the reaction yield is lower than sonication within a longer time. As could be guessed, there is a meaningful synergistic effect among catalyst (active catalytic sites) and US waves. Actually, collapsing the cavitation bubbles provided localized "hot spots" with high pressures that were responsible for the required bonding energy and molecular fragmentation. From the physical aspect, US irradiation facilitated the dispersion of the nanocatalyst in the media and therefore higher active surface area was generated. All of these phenomena can cause a reaction to take place rapidly. Next, the effect of solvents was variably investigated in the synthesis of (4a) as a model compound. Ethanol, acetonitrile, methanol, and THF afforded medium yields and more times (Table 2, entries 8, 10, 12, and 14). When the reaction was done in dioxane, toluene and DMF, the product yields were respectively about 55,60 , and $62 \%$. Based on the results, $\mathrm{H}_{2} \mathrm{O}$ is an optimum solvent for the preparation of 4a. As a result, the use of $10 \mathrm{~mol} \%$ of the hydrothermal-treated $\mathrm{Co}_{3} \mathrm{O}_{4}$ @crosslinked $\mathrm{p}[\mathrm{AVIM}] \mathrm{Br}$ catalyst in $\mathrm{H}_{2} \mathrm{O}$ as solvent under US condition can be considered as the optimal condition $(40 \mathrm{kHz}, 100 \mathrm{~W})$.

Subsequently, to demonstrate the scope and applicability of this catalyst in the one-pot three-component synthesis of spiro2,3-disubstituted-4-thiazolidinone derivatives, the reaction was extended to other substituted isatins, and various primary amines (Tables 3 and 4). All the prepared compounds have been characterized by IR, ${ }^{1} \mathrm{HNMR},{ }^{13} \mathrm{CNMR}$, and elemental analysis. The above results clearly showed that the present catalytic procedure is extendable to a great diversity of substrates to make a variety-oriented library of spiro-4-thiazolidinone. Changing the electronic structure of the substituents (C5 of isatins) was also acceptable with high yields. An aryl amine including electron-donating substituents (methoxy, methyl, and hydroxy) reacted well with thioglycolic acid and isatin derivatives generated the desired spiro products in excellent yields whereas the amines have less reactive electron withdrawing substituents, such as (chloro, and fluoro) that were found to be sluggish good yields. While the reactions of various isatins and thioglycolic acid with benzylamine were afforded the products in higher yields. 
Table 3 Scope of catalytic activity of hydrothermal treated $\mathrm{CO}_{3} \mathrm{O}_{4}$ (acrosslinked p[AVIM]Br for synthesis of spiro-4-thiazolidinones ${ }^{a}$

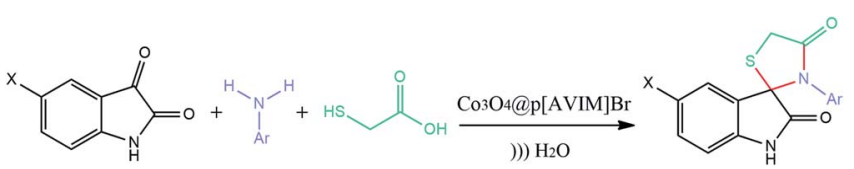

\begin{tabular}{|c|c|c|c|c|c|}
\hline Entry & $\mathrm{X}$ & Amine & Product & Time (min) & Yield $\%{ }^{b}$ \\
\hline 1 & $\mathrm{H}$ & Aniline & 4a & 6 & 94 \\
\hline 2 & $\mathrm{H}$ & 4-Chloroaniline & $4 \mathbf{b}$ & 8 & 92 \\
\hline 3 & $\mathrm{H}$ & 4-Methoxyaniline & $4 c$ & 6 & 96 NEW \\
\hline 4 & $\mathrm{H}$ & Benzylamine & 4d & 7 & 96 \\
\hline 5 & $\mathrm{H}$ & 4-Fluoroaniline & $4 e$ & 10 & 92 \\
\hline 6 & $\mathrm{H}$ & 2-Chloro-5-(trifluoromethyl)aniline & 4f & 6 & 98 \\
\hline 7 & $\mathrm{H}$ & 4-Aminophenol & $4 \mathrm{~g}$ & 7 & 96 \\
\hline 8 & $\mathrm{Cl}$ & Aniline & $4 h$ & 4 & 97 \\
\hline 9 & $\mathrm{Cl}$ & 4-Methylaniline & $4 i$ & 4 & 95 \\
\hline 10 & $\mathrm{Cl}$ & Benzylamine & $4 \mathbf{j}$ & 7 & 96 \\
\hline 11 & $\mathrm{Cl}$ & 4-Methoxyaniline & $4 \mathbf{k}$ & 4 & 98 NEW \\
\hline 12 & $\mathrm{Br}$ & Aniline & 41 & 6 & 95 \\
\hline 13 & $\mathrm{Br}$ & Benzylamine & $4 \mathrm{~m}$ & 6 & 95 \\
\hline 14 & $\mathrm{Me}$ & Aniline & $4 n$ & 10 & 92 \\
\hline 15 & $\mathrm{Me}$ & 4-Methylaniline & 40 & 9 & 93 \\
\hline 16 & $\mathrm{Me}$ & 4-Fluoroaniline & $4 p$ & 12 & 90 \\
\hline
\end{tabular}

${ }^{a}$ Reactions conditions: isatin $(1 \mathrm{mmol})$, amine $(1 \mathrm{mmol})$ and thioglycolic acid $(1 \mathrm{mmol})$, in the presence of hydrothermal treated $\mathrm{Co}_{3} \mathrm{O}_{4}$ @crosslinked p[AVIM] Br $(0.01 \mathrm{~g}) .{ }^{b}$ Isolated yield.

Table 4 Scope of catalytic activity of hydrothermal treated $\mathrm{CO}_{3}-$ $\mathrm{O}_{4}$ (acrosslinked $\mathrm{p}[\mathrm{AVIM}] \mathrm{Br}$ for synthesis of spiro-4-thiazolidinones ${ }^{a}$

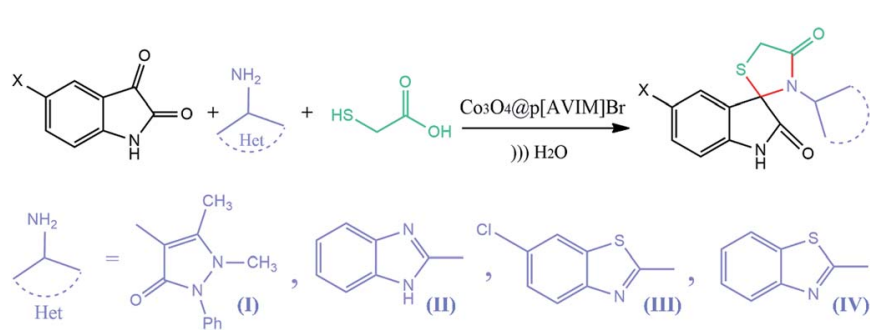

\begin{tabular}{llllll}
\hline Entry & $\mathrm{X}$ & Amine & Product & Time (min) & Yield\% $^{b}$ \\
\hline 1 & H & (I) & $\mathbf{4 q}$ & 5 & 92 \\
2 & $\mathrm{Br}$ & (I) & $\mathbf{4 r}$ & 5 & 96 \\
3 & $\mathrm{Me}$ & (I) & $\mathbf{4 s}$ & 8 & 93 \\
4 & $\mathrm{H}$ & (II) & $\mathbf{4 t}$ & 6 & 95 \\
5 & $\mathrm{Cl}$ & (II) & $\mathbf{4 u}$ & 98 & 7 \\
6 & $\mathrm{Me}$ & (II) & $\mathbf{4 v}$ & 10 & 91 \\
7 & $\mathrm{H}$ & (IV) & $\mathbf{4 w}$ & 6 & 95 \\
8 & $\mathrm{Cl}$ & (IV) & $\mathbf{4 x}$ & 5 & 98 \\
9 & $\mathrm{Me}$ & (IV) & $\mathbf{4 y}$ & 8 & 92 \\
10 & $\mathrm{H}$ & (III) & $\mathbf{4 z}$ & 7 & 96
\end{tabular}

${ }^{a}$ Reactions conditions: isatin $(1 \mathrm{mmol})$, amine $(1 \mathrm{mmol})$ and thioglycolic acid $(1 \mathrm{mmol})$, in the presence of hydrothermal treated $\mathrm{Co}_{3} \mathrm{O}_{4}$ @crosslinked $\mathrm{p}[\mathrm{AVIM}] \mathrm{Br}(0.01 \mathrm{~g}) .{ }^{b}$ Isolated yield.

In addition, a comparative study was performed between synthesized $\mathrm{Co}_{3} \mathrm{O}_{4} @ \mathrm{p}[\mathrm{AVIM}] \mathrm{Br}$ and previously reported catalyst for the synthesis of spiro-2,3-disubstituted-4-thiazolidinone derivatives. As shown in Table 5, the highest yield and shortest reaction times belong to prepared porous PIL under mild and green conditions.

The proposed reaction pathway mechanism for the preparation of spiro[indoline-3,2'-thiazolidinones] in the presence of prepared PIL is shown in Scheme 1. Herein, we introduce a new porous PIL including two different catalytic natures. Applied PIL including different acidic and basic active sites, can activate reaction via different routes by noncovalent interactions between two ionic groups of opposite charge (approaching isatin and aniline to initiate reaction). On the other hand, hydrogen bonding (a branch of noncovalent interactions) makes carbonyl group of isatin more susceptible to aniline nucleophilic addition. According to literatures, ${ }^{50,51}$ at the initial step of the catalytic pathway, the sonocatalyst facilitated the condensation of primary amine and isatin for the generation of the protonated Schiff base A through dual acid-basic sites. Then, imine (A) reacts with thioglycolic acid to generate the carbon-sulfur bond. The gem-diol compound generates through an intramolecular cyclization, and the desired product (4a) was obtained after the release of a water molecule. Furthermore, ultrasound irradiations have a significant role in multicomponent reactions. In general, asymmetric collapse form micro liquid jet with high speed enhanced the heat and mass transfer among the pores in the presence of ultrasound waves. This liquid jets activated the heterogeneous magnetic catalyst and improved the mass transfer by the disruption of the interfacial boundary layers. 
Table 5 Comparative study between reported catalyst and $\mathrm{CO}_{3} \mathrm{O}_{4} @$ acrosslinked p[AVIM] Br

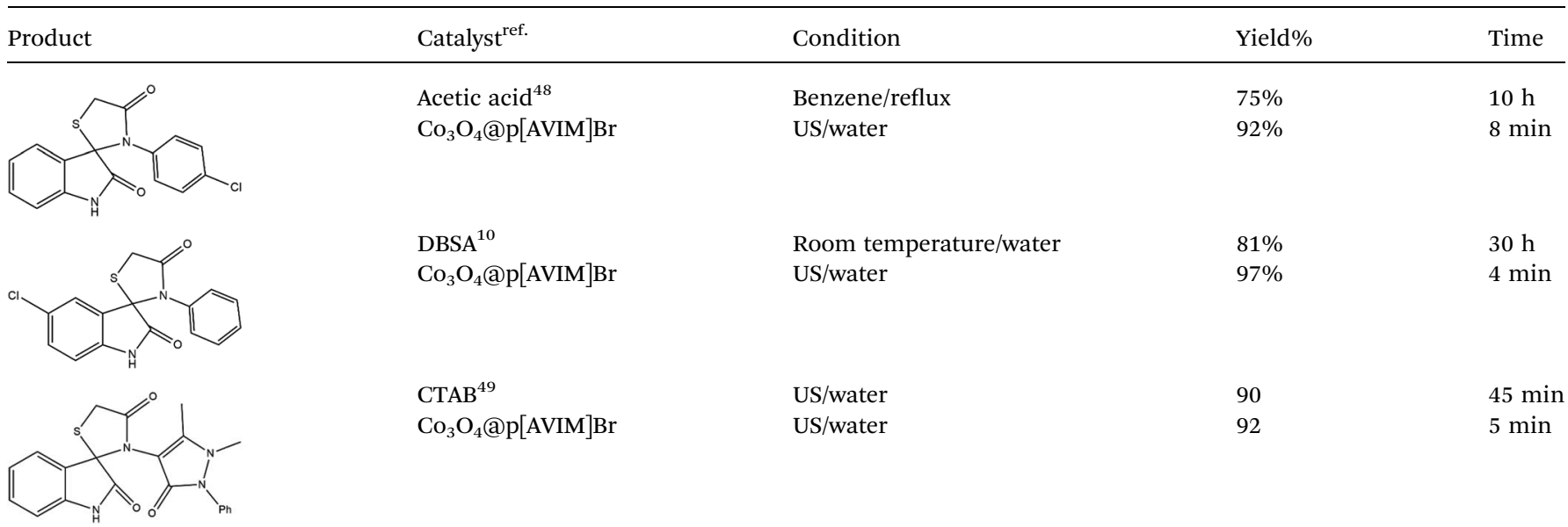

Recoverability is known as one of the most important properties of the fabricated catalyst. At the end of the reaction, the nanocatalyst was magnetically separated and then the catalyst was washed three times with ethanol and $\mathrm{H}_{2} \mathrm{O}$, dried $24 \mathrm{~h}$, and reused directly with fresh substrates. It was shown that the hydrothermal treated $\mathrm{Co}_{3} \mathrm{O}_{4} @$ @crosslinked p[AVIM] $\mathrm{Br}$ could be recovered from the eight runs without any noticeable loss of its activity (Fig. 8). Next, to explore the probable change of

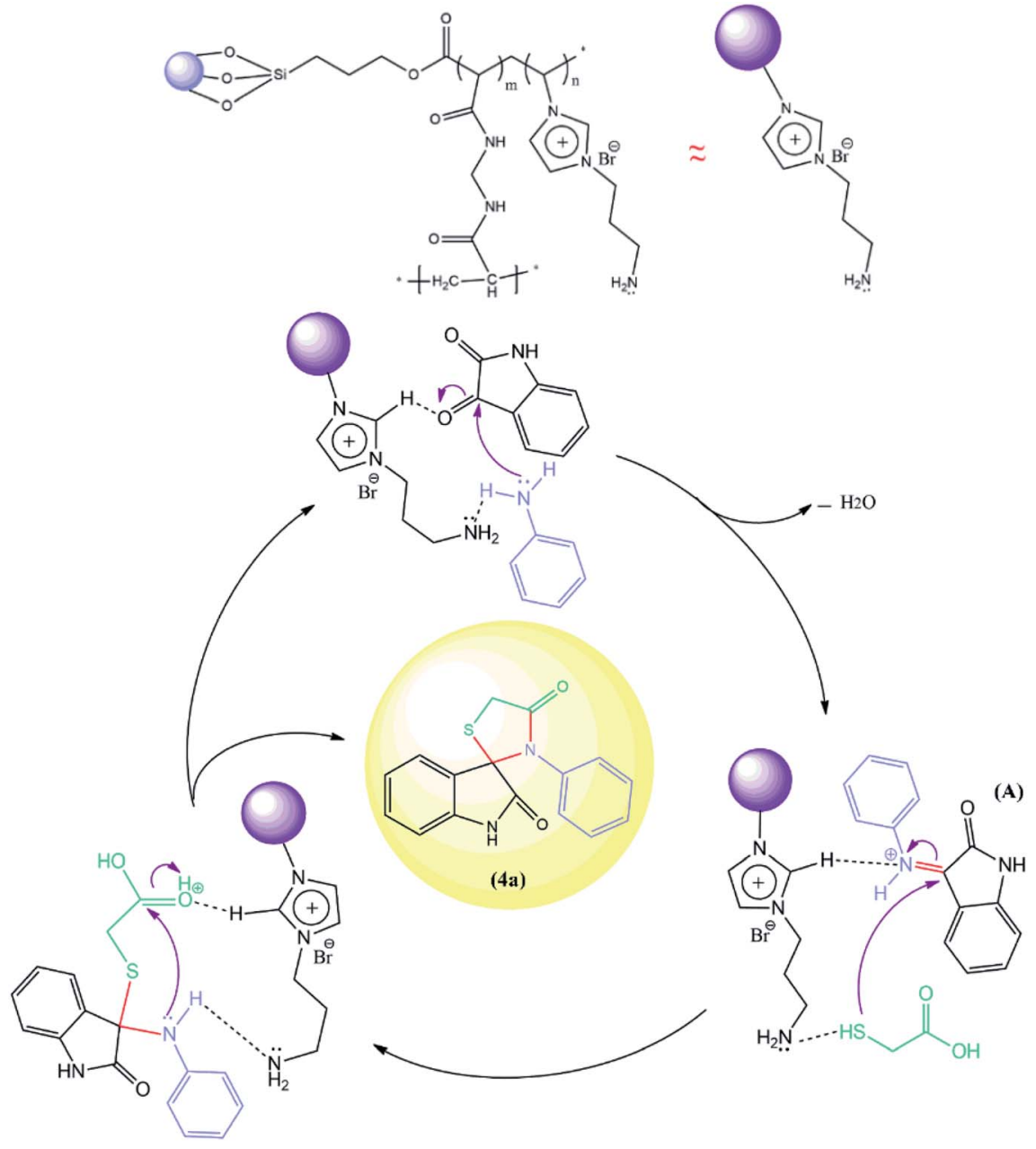

Scheme 1 The catalytic cycle for the synthesis of spiro-4-thiazolidinones (4a). 


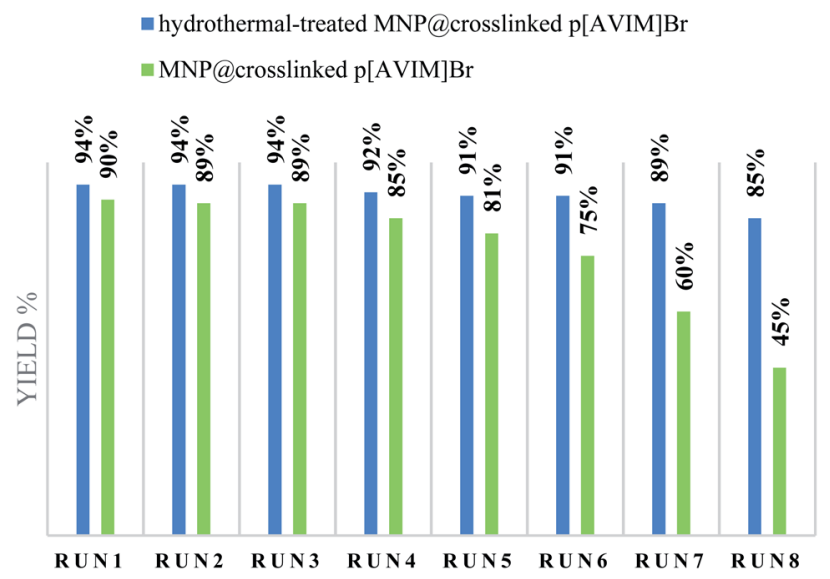

Fig. 8 Recyclability of sonocatalyst.

sonocatalyst morphology, the FESEM images of the recovered $\mathrm{Co}_{3} \mathrm{O}_{4} @$ crosslinked $\mathrm{p}[\mathrm{AVIM}] \mathrm{Br}$ after eight reaction runs were recorded for two different polymerization methods (Fig. 9). As shown, recycling did not significant change the morphology of hydrothermal treated sample (Fig. 9A), so the propose catalyst has high chemical stability.

\section{Experimental}

\subsection{Chemicals and apparatus}

1-Vinylimidazole (Alfa Aesar, 99\%), 3-bromopropylamine hydrobromide (99\%), ethyl acetate (ACS reagent, $\geq 99.5 \%$ ), and 4,4'-azobis(4-cyanopentanoic acid) ( $\geq 98 \%)$ were obtained from Aldrich Chemical. All other chemical compounds were chosen from Merck Chemical. Fourier transform infrared spectra were recorded on an ABB Bomem MB-100 FTIR spectrometer. The XRD pattern was recorded on a Brucker AXS D8 diffractometer (Cu-K $\alpha$ radiation). Thermo Gravimetric Analysis (TGA) was performed using a TGA Q 50 analyzer under the nitrogen atmosphere. The pore size distribution curves and nitrogen sorption isotherms were checked on a BELSORP-MINI analyzer while the samples were degassed at $473 \mathrm{~K}$ for $3 \mathrm{~h}$. The specific surface area of samples was determined by Brunauer-EmmettTeller (BET) calculation. Pore size distributions were estimated

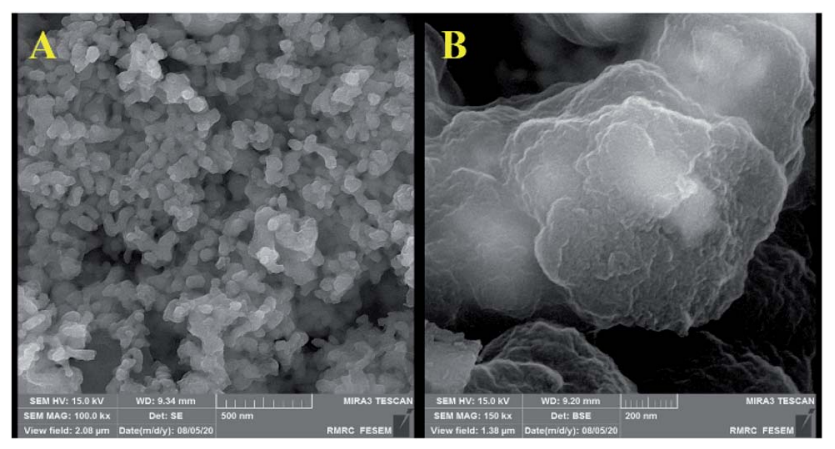

Fig. 9 FE-SEM images of the recovered sonocatalyst after eight reaction run under the optimum reaction condition; (A) hydrothermal, and (B) classical precipitation polymerization. using Barrett-Joyner-Halenda (BJH) method. FE-SEM images were prepared with MIRA3TESCAN-XMU. Elemental analyses (EDS) were obtained on a PerkinElmer analyzer. Vibrating Sample Magnetometer (VSM) was made by MDK-I. R. Iran. NMR spectra were recorded on a Bruker $300 \mathrm{MHz}$ spectrometer with TMS as an internal standard and DMSO- $\mathrm{d}^{6}$ as solvent.

\subsection{Synthesis of vinyl functionalized $\mathrm{Co}_{3} \mathrm{O}_{4} \mathrm{NPs}$}

$\mathrm{Co}_{3} \mathrm{O}_{4}$ NPs were prepared based on our previously reported procedure. $^{52}$ Cobalt(II) nitrate hexahydrate $(8.60 \mathrm{~g})$ was dispersed in ethanol $(100 \mathrm{~mL})$ at room temperature for $30 \mathrm{~min}$. Then, oxalic acid ( $2.14 \mathrm{~g})$ was swiftly added and the mixture was stirred for $90 \mathrm{~min}$ at $40{ }^{\circ} \mathrm{C}$. The obtained pink precipitate was calcined at $400{ }^{\circ} \mathrm{C}$ for $2 \mathrm{~h}$. A mixture of $\mathrm{Co}_{3} \mathrm{O}_{4} \mathrm{MNP}(1 \mathrm{~g})$ in $50 \mathrm{~mL}$ ethanol was prepared and the ammonia solution $(2 \mathrm{~mL})$ was then added to it. Next, 3-(trimethoxysilyl)propyl methacrylate (MPS) $(10 \mathrm{mmol})$ was slowly added and the solution was stirred under reflux condition for $24 \mathrm{~h}$. Finally, the MPS coated $\mathrm{Co}_{3} \mathrm{O}_{4}$ NPs (MNP@MPS) were separated by an external magnet and washed with ethanol $(3 \times 30 \mathrm{~mL})$ to remove the unreacted compounds and then was dried overnight at $45{ }^{\circ} \mathrm{C}$.

\subsection{Synthesis of the ionic monomer}

1-Aminopropyl-3-vinylimidazolium bromide ([AVIM]Br) was prepared under ultrasound condition for the first time. Briefly, 1-vinyl imidazole $(3 \mathrm{mmol})$ and $10 \mathrm{~mL}$ ethanol were added to a two-necked flask equipped and then 3-bromopropylamine hydrobromide ( $3 \mathrm{mmol}$ ) was added into the flask and sonicated under nitrogen atmosphere. Finally, $[\mathrm{AVIM}] \mathrm{Br} \cdot \mathrm{HBr}(5 \mathrm{mmol})$ was dissolved in the water $(10 \mathrm{~mL})$ and then equimolar sodium hydroxide was added and sonicated for $10 \mathrm{~min}$ at room temperature to form the isolated [AVIM] Br. The chemical structure of the product was determined using the FTIR, ${ }^{1} \mathrm{H}$ NMR, and ${ }^{13} \mathrm{C}$ NMR analysis ([AVIM] Br yield $\left.=90 \%\right)$. White solid, yield: $90 \%$; IR $\left(\mathrm{CHCl}_{3}\right) \nu_{\max }: 3440,2930,2845,1648,1228$, 1168, 1020, 932, 824, $660 \mathrm{~cm}^{-1},{ }^{1} \mathrm{H}$ NMR (300 MHz, DMSO- $\left.d_{6}\right)$ $\delta(\mathrm{ppm}): 7.95(\mathrm{~s}, 1 \mathrm{H}), 7.54(\mathrm{~s}, 1 \mathrm{H}), 7.01(\mathrm{~s}, 1 \mathrm{H}), 5.50-5.77(\mathrm{~d}, 2 \mathrm{H})$, $5.18(\mathrm{~s}, 1 \mathrm{H}), 4.84-4.80(\mathrm{t}, 1 \mathrm{H}), 3.60-3.5(\mathrm{t}, 2 \mathrm{H}), 2.90-2.84(\mathrm{t}, 2 \mathrm{H})$, 2.10-2.05 (m, 2H). ${ }^{13} \mathrm{C}$ NMR (100 MHz, DMSO-d $\left.\mathrm{d}_{6}\right) \delta(\mathrm{ppm})$ : 139.7, 124.5, 114.0, 107.5, 35.0, 33.3, 29.3.

\subsection{Fabrication of porous poly ionic liquid through the precipitation polymerizations}

$\mathrm{Co}_{3} \mathrm{O}_{4} @ M P S(0.5 \mathrm{~g}), 1$-aminoethyl-3-vinylimidazolium bromide $(0.45 \mathrm{~g}, 0.005 \mathrm{~mol})$ and $N, N^{\prime}$-methylenebis acrylamide $(0.46 \mathrm{~g}$, $0.003 \mathrm{~mol}$ ) as crosslinker were dissolved into $10 \mathrm{~mL}$ dry methanol. The preparation procedure was followed by the addition of ACPA (1\% mol, $0.029 \mathrm{~g})$ which was refluxed for $3 \mathrm{~h}$. Next, the obtained gray powder was washed with water $(2 \times 20)$ and dried at $40{ }^{\circ} \mathrm{C}$ for about $18 \mathrm{~h}$.

\subsection{Fabrication of porous poly ionic liquid through the hydrothermal precipitation polymerization}

As a typical procedure, $\mathrm{Co}_{3} \mathrm{O}_{4} @$ MPS $(0.5 \mathrm{~g})$, 1-aminoethyl-3vinylimidazolium bromide $(0.45 \mathrm{~g}, \quad 0.005 \mathrm{~mol}), \quad N, N^{\prime}-$ 
methylenebis acrylamide (0.46 g, $0.003 \mathrm{~mol})$, and ACPA ( $1 \% \mathrm{~mol}, 0.029 \mathrm{~g})$ were mixed in $10 \mathrm{~mL}$ deionized water. After vigorous stirring at ambient temperature for $2 \mathrm{~h}$, the mixture was transferred into steel autoclave at $100{ }^{\circ} \mathrm{C}$ for $24 \mathrm{~h}$. Finally, the dark monolithic solid was collected and kept in a vacuum drying oven at $40{ }^{\circ} \mathrm{C}$ for $12 \mathrm{~h}$. The specific fabrication rout of porous PIL is shown in Scheme 2.

\subsection{General preparation of spiro-4-thiazolidinones}

A mixture of isatin ( $1 \mathrm{mmol})$, thioglycolic acid $(1 \mathrm{mmol})$, various primary amines $(1 \mathrm{mmol})$, and synthesized $\mathrm{Co}_{3} \mathrm{O}_{4} @$ crosslinked $\mathrm{p}$ [AVIM]Br as catalyst were dissolved in water and sonicated in an ultrasonic bath at $25{ }^{\circ} \mathrm{C}$ for appropriate times. The completion of the reaction was monitored by TLC and the catalyst was then magnetically separated. Finally, the crude precipitate was filtered and then recrystallized from $\mathrm{EtOH}$ to obtain a pure solid product. The products were characterized by ${ }^{1} \mathrm{H} \mathrm{NMR},{ }^{13} \mathrm{C} \mathrm{NMR}$, IR, and elemental analysis (spectral data of compounds mentioned in $\mathrm{ESI}_{\dagger} \dagger$ ).

\subsection{Spectral data of the all compounds}

3'-Phenyl-spiro[3H-indole-3,2'-thiazolidine]-2,4'-(1H)-dione (4a). Mp $233{ }^{\circ} \mathrm{C}(\mathrm{MeOH}) .{ }^{1} \mathrm{H}$ NMR (300 MHz, DMSO-d 6 ) $\delta / \mathrm{ppm}$ : $3.46\left(\mathrm{~d}, 2 \mathrm{H}, \mathrm{CH}_{2}\right), 6.34-7.60(\mathrm{~m}, 9 \mathrm{H}, \mathrm{Ar}-\mathrm{H}), 11.16(\mathrm{~s}, 1 \mathrm{H}, \mathrm{NH})$. ${ }^{13} \mathrm{C}$ NMR (100 MHz, DMSO-d 6 ) $\delta / \mathrm{ppm:} \mathrm{172.1,} \mathrm{167.1,} \mathrm{142.4,} \mathrm{136.0,}$ 134.0, 126.1, 125.2, 123.5, 119.7, 116.8, 108.7, 70.9, 31.2. Anal. calcd for $\mathrm{C}_{16} \mathrm{H}_{12} \mathrm{~N}_{2} \mathrm{O}_{2} \mathrm{~S}, \%$ C, 64.85; H, 4.08; N, 9.45. Found, \%: C, 64.84; H, 4.05; N, 9.43.

$3^{\prime}$-(4-Chlorophenyl)-spiro[3H-indole-3, $\mathbf{2}^{\prime}$-thiazolidine]-2, $\mathbf{4}^{\prime}$ (1H)-dione (4b). Mp 170-173 ${ }^{\circ} \mathrm{C}(\mathrm{MeOH}) .{ }^{1} \mathrm{H}$ NMR $(300 \mathrm{MHz}$, DMSO-d $\left.{ }_{6}\right) \delta / p p m: 2.48\left(2 \mathrm{H}, \mathrm{CH}_{2}\right), 6.75-7.22(\mathrm{~m}, 8 \mathrm{H}, \mathrm{Ar}-\mathrm{H}), 10.38$ (s, 1H, NH). ${ }^{13} \mathrm{C}$ NMR (100 MHz, DMSO-d 6 ) $\delta / p p m: ~ 173.8, ~ 170.9$, 145.9, 133.9, 124.6, 123.9, 122.2, 120.0, 115.2, 113.5, 111.1, 71.8, 31.2. Anal. calcd for $\mathrm{C}_{16} \mathrm{H}_{11} \mathrm{ClN}_{2} \mathrm{O}_{2} \mathrm{~S}, \% \mathrm{C}, 58.09 ; \mathrm{H}, 3.35 ; \mathrm{N}, 8.47$. Found, \%: C, 58.08; H, 3.33; N, 8.50.

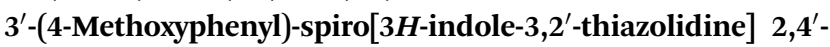
(1H)-dione (4c). Mp 168-170 ${ }^{\circ} \mathrm{C}$. IR $\left(\mathrm{CHCl}_{3}\right) \nu_{\max }: 3280,2833$, 1738, 1612, 1500, 1462, 1333, $752 \mathrm{~cm}^{-1},{ }^{1} \mathrm{H}$ NMR $(300 \mathrm{MHz}$, DMSO-d $\left.{ }_{6}\right) \delta /$ ppm: $2.48\left(\mathrm{~s}, 3 \mathrm{H}, \mathrm{CH}_{3}\right), 3.75-3.81\left(\mathrm{q}, 2 \mathrm{H}, \mathrm{CH}_{2}\right.$ ),

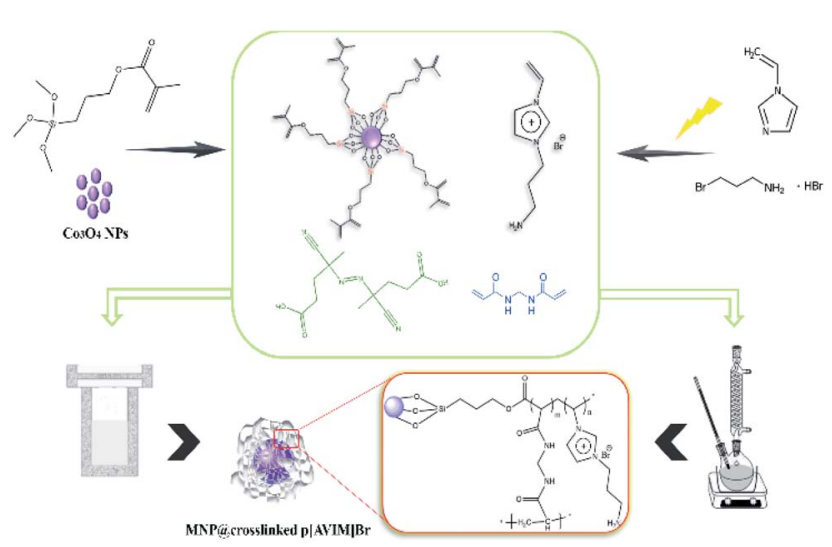

Scheme 2 Schematic representation of the fabrication of $\mathrm{CO}_{3} \mathrm{O}_{4}$ @ crosslinked $\mathrm{p}[\mathrm{AV} \mathrm{IM}] \mathrm{Br}$ under two different polymerization approach.
6.74-7.35 (m, 8H, Ar-H), 10.92 (s, $1 \mathrm{H}, \mathrm{NH}) .{ }^{13} \mathrm{C}$ NMR (100 MHz, DMSO-d $_{6}$ ) $\delta /$ ppm: 176.83, 163.86, 156.92, 145.94, 133.90, 126.96, 123.93, 122.26, 120.37, 116.47, 115.20, 113.94, 87.96, 55.76, 32.96. Anal. calcd for $\mathrm{C}_{17} \mathrm{H}_{14} \mathrm{~N}_{2} \mathrm{O}_{3} \mathrm{~S}, \%$ C, 62.56; H, 4.32; N, 8.58. Found, \%: C, 62.57; H, 4.35; N, 8.60.

$\mathbf{3}^{\prime}$-Benzyl-spiro[indoline-3, $\mathbf{2}^{\prime}$-thiazolidine]-2, $\mathbf{4}^{\prime}$-dione (4d). Mp 180-182 ${ }^{\circ} \mathrm{C}(\mathrm{MeOH}) .{ }^{1} \mathrm{H}$ NMR (300 MHz, DMSO-d $\left.{ }_{6}\right) \delta / p p m:$ 2.41-2.48 (2H, $\left.\mathrm{CH}_{2}\right), 3.71\left(2 \mathrm{H}, \mathrm{CH}_{2}\right), 6.71-7.63(\mathrm{~m}, 9 \mathrm{H}, \mathrm{Ar}-\mathrm{H})$, 10.25 (s, 1H, NH). ${ }^{13} \mathrm{C}$ NMR (100 MHz, DMSO-d $\left.{ }_{6}\right) \delta / p p m: ~ 177.6$, 170.6, 144.3, 140.4, 134.6, 127.6, 125.4, 119.9, 115.1, 111.9, 75.3, 55.7, 22.2. Anal. calcd for $\mathrm{C}_{17} \mathrm{H}_{14} \mathrm{~N}_{2} \mathrm{O}_{2} \mathrm{~S}, \%$ C, 65.79; H, 4.55; N, 9.03. Found, \%: C, 65.78; H, 4.51; N, 9.01.

$3^{\prime}$-(4-Fluorophenyl)-spiro[3H-indole-3, $2^{\prime}$-thiazolidine]-2,4' (1H) dione (4e). Mp 245-244 ${ }^{\circ} \mathrm{C}(\mathrm{MeOH}) .{ }^{1} \mathrm{H}$ NMR $(300 \mathrm{MHz}$, DMSO-d ${ }_{6}$ ) $\delta /$ ppm: 3.78 (d, 1H, CH), 4.39 (d, 1H, CH), 6.69-7.56 (m, 8H, Ar-H), 9.97 (s, 1H, NH). 178.4, 167.9, 155.4, 151.2, 148.4, 140.5, 133.3, 132.4, 130.6, 126.8, 123.2, 122.6, 118.1, 116.5, 72.7, 36.5. Anal. calcd for $\mathrm{C}_{16} \mathrm{H}_{11} \mathrm{FN}_{2} \mathrm{O}_{2} \mathrm{~S}, \%$ : C, 61.14; H, 3.53; N, 8.91. Found, \%: C, 61.11; H, 3.51; N, 8.90.

3'-(5-Trifluoromethyl-2-chlorophenyl)-spiro-[3H-indole-3,2'thiazolidine]-2,4'-(1H)-dione (4f). $\mathrm{Mp} 145{ }^{\circ} \mathrm{C}(\mathrm{MeOH}) .{ }^{1} \mathrm{H}$ NMR (300 MHz, DMSO-d ${ }_{6}$ ) $\delta /$ ppm: $3.87\left(\mathrm{~d}, 2 \mathrm{H}, \mathrm{CH}_{2}\right.$ ), 6.78-7.31 (m, $7 \mathrm{H}, \mathrm{Ar}-\mathrm{H}), 9.19$ (s, 1H, NH). ${ }^{13} \mathrm{C}$ NMR $\left(75.47 \mathrm{MHz}, \mathrm{DMSO}^{-\mathrm{d}_{6}}\right) \delta /$ ppm: 179.9, 174.4, 146.0, 135.1, 134.1, 130.5, 129.2, 125.7, 125.0, $122.5,120.4,117.9,113.5,112.7,100.0,70.2,21.0$. Anal. calcd for $\mathrm{C}_{17} \mathrm{H}_{10} \mathrm{ClF}_{3} \mathrm{~N}_{2} \mathrm{O}_{2} \mathrm{~S} ; \% \mathrm{C}, 51.20 ; \mathrm{H}, 2.53 ; \mathrm{N}, 7.02$. Found C, 51.17; $\mathrm{H}, 2.52$; N, 7.04 .

$3^{\prime}$-(4-Hydroxyphenyl)-spiro[3 $\mathrm{H}$-indole-3, $\mathbf{2}^{\prime}$-thiazolidine $]-2, \mathbf{4}^{\prime}$ (1H)-dione (4g). $\mathrm{Mp}>230{ }^{\circ} \mathrm{C}(\mathrm{MeOH}) .{ }^{1} \mathrm{H}$ NMR $(300 \mathrm{MHz}$, DMSO-d 6 ) $\delta /$ ppm: $3.56\left(2 \mathrm{H}, \mathrm{CH}_{2}\right), 6.51-7.63(\mathrm{~m}, 8 \mathrm{H}, \mathrm{Ar}-\mathrm{H}), 9.04$ (s, 1H, OH), 10.21 (s, 1H, NH). ${ }^{13} \mathrm{C}$ NMR (100 MHz, DMSO-d 6 ) $\delta /$ ppm: 180.1, 168.2, 162.2, 159.5, 143.2, 138.3, 136.3, 127.5, 124.9, 122.7, 112.8, 109.8, 108.9, 78.4, 33.0. Anal. calcd for $\mathrm{C}_{16} \mathrm{H}_{12} \mathrm{~N}_{2} \mathrm{O}_{3} \mathrm{~S}$, \% C, 61.53; H, 3.87; N, 8.97. Found, \%: C, 61.55; $\mathrm{H}, 3.85$; N, 9.00.

5-Chloro-3' -phenylspiro[indoline-3,2' -thiazolidine]-2,4' dione (4h). $\mathrm{Mp} 306{ }^{\circ} \mathrm{C}(\mathrm{MeOH}) .{ }^{1} \mathrm{H}$ NMR (300 MHz, DMSO-d 6 ) $\delta /$ ppm: 4.03 (d, 2H, $\mathrm{CH}_{2}$ ), 6.76-7.69 (m, 8H, Ar-H), 10.90 (s, 1H, $\mathrm{NH}) .{ }^{13} \mathrm{C}$ NMR (100 MHz, DMSO-d 6 ) $\delta / \mathrm{ppm}: 176.2,171.9,140.4$, 136.2, 131.3, 129.6, 128.7, 128.2, 127.2, 127.0, 126.6, 112.4, 69.6, 32.5. Anal. calcd for $\mathrm{C}_{16} \mathrm{H}_{11} \mathrm{ClN}_{2} \mathrm{O}_{2} \mathrm{~S}$, \% C, 58.09; H, 3.35; N, 8.47. Found, \%: C, 58.05; H, 3.35; N, 8.42.

3'-(4-Methyl)-5-chlorospiro[3H-indole-3, $2^{\prime}$-thiazolidine]-2,4'(1H)-dione (4i). Mp 185-186 ${ }^{\circ} \mathrm{C}(\mathrm{MeOH}) .{ }^{1} \mathrm{H}$ NMR $(300 \mathrm{MHz}$, DMSO-d ${ }_{6}$ ) $\delta$ ppm: 2.35 (s, 3H, $\mathrm{CH}_{3}$ ), 3.30 (d, 2H, $\mathrm{CH}_{2}$ ), 6.38-7.40 (m, 7H, Ar-H), 11.07 (s, 1H, NH). ${ }^{13} \mathrm{C}$ NMR (100 MHz, DMSO-d 6 ) $\delta / \mathrm{ppm}: 179.5,161.7,159.0,152.9,149.5,143.3,137.7,127.6$, 125.0, 123.5, 111.1, 109.7, 76.3, 50.8, 32.1. Anal. calcd for $\mathrm{C}_{17^{-}}$ $\mathrm{H}_{13} \mathrm{ClN}_{2} \mathrm{O}_{2} \mathrm{~S}$, \% C, 59.21; H, 3.80; N, 8.12. Found, \%: C, 59.25; H, $3.82 ; \mathrm{N}, 8.12$.

3'-Benzyl-5-chlorospiro[indoline-3, $\mathbf{2}^{\prime}$-thiazolidine]-2,4'-dione (4j). Mp 186-188 ${ }^{\circ} \mathrm{C}(\mathrm{MeOH}) .{ }^{1} \mathrm{H}$ NMR (300 MHz, DMSO-d 6 ) $\delta /$ ppm: 3.31 (d, 2H, benzyl $\left.\mathrm{CH}_{2}\right), 4.00\left(\mathrm{~d}, 2 \mathrm{H}, \mathrm{CH}_{2}\right), 6.71-8.00(\mathrm{~m}$, $8 \mathrm{H}, \mathrm{Ar}-\mathrm{H}), 10.54$ (s, 1H, NH). ${ }^{13} \mathrm{C}$ NMR (100 MHz, DMSO-d 6 ) $\delta /$ ppm: 175.8, 172.1, 142.0, 135.5, 131.3, 128.08, 128.0, 127.4, 126.3, 123.6, 122.3, 110.6, 68.5, 46.1, 32.1. Anal. calcd for 
$\mathrm{C}_{17} \mathrm{H}_{13} \mathrm{ClN}_{2} \mathrm{O}_{2} \mathrm{~S}, \%$ C, 59.21; H, 3.80; N, 8.12. Found, \%: C, 59.20; $\mathrm{H}, 3.78$; N, 8.11.

3'-(4-Methoxyphenyl)-5-chloro-3' -phenylspiro[3H-indole-3,2' thiazolidine]-2,4'-(1H)-dione (4k). Mp 186-188 ${ }^{\circ} \mathrm{C}(\mathrm{MeOH}) . \mathrm{IR}$ $\left(\mathrm{CHCl}_{3}\right) \nu_{\text {max }}: 3448,3224,2931,2835,1736,1608,1597,1504$, 1462, 1292, 1254, 1034, $837 \mathrm{~cm}^{-1},{ }^{1} \mathrm{H}$ NMR (300 MHz, DMSO-d 6 )

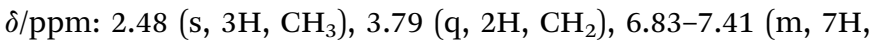
$\mathrm{Ar}-\mathrm{H}), 11.08$ (s, 1H, NH). ${ }^{13} \mathrm{C}$ NMR (100 MHz, DMSO-d 6 ) $\delta / \mathrm{ppm}$ : $173.8,163.8,157.9,145.9$, 133.9, 124.6, 123.9, 122.2, 120.0, 115.2, 113.9, 87.9, 55.8, 32.5. Anal. calcd for $\mathrm{C}_{17} \mathrm{H}_{13} \mathrm{ClN}_{2} \mathrm{O}_{3} \mathrm{~S}, \%$ C, 56.59; H, 3.63; N, 7.76. Found, \%: C, 56.57; H, 3.62; N, 7.74.

5-Bromo- $\mathbf{3}^{\prime}$-phenylspiro[indoline-3,2' -thiazolidine]-2,4'-

dione (4l). $\mathrm{Mp} 306{ }^{\circ} \mathrm{C}(\mathrm{MeOH}) .{ }^{1} \mathrm{H}$ NMR (300 MHz, DMSO-d $\left.\mathrm{d}_{6}\right) \delta /$ ppm: 3.8 (s, 2H, $\mathrm{CH}_{2}$ ), 6.92-8.16 (m, 8H, Ar-H), $11.17(\mathrm{~s}, 1 \mathrm{H}$, $\mathrm{NH}) .{ }^{13} \mathrm{C}$ NMR $\left(100 \mathrm{MHz}, \mathrm{DMSO}-\mathrm{d}_{6}\right) \delta / \mathrm{ppm}: 179.6,174.4,154.9$, 140.4, 135.0, 134.6, 129.6, 125.2, 119.4, 114.1, 111.2, 110.9, 72.1, 38.5. Anal. calcd for $\mathrm{C}_{16} \mathrm{H}_{11} \mathrm{BrN}_{2} \mathrm{O}_{2} \mathrm{~S}, \% \mathrm{C}, 51.21 ; \mathrm{H}, 2.95 ; \mathrm{N}$, 7.47. Found, \%: C, 51.25; H, 2.93; N, 7.42.

3'-Benzyl-5-bromospiro[indoline-3,2' -thiazolidine]-2,4'dione (4m). Mp 190-192 ${ }^{\circ} \mathrm{C}(\mathrm{MeOH}) .{ }^{1} \mathrm{H}$ NMR $(300 \mathrm{MHz}$, DMSO$\left.\mathrm{d}_{6}\right) \delta /$ ppm: $3.31\left(\mathrm{~d}, 2 \mathrm{H}\right.$, benzyl $\left.\mathrm{CH}_{2}\right), 4.00\left(\mathrm{~d}, 2 \mathrm{H}, \mathrm{CH}_{2}\right), 6.71-8.00$ (m, 8H, Ar-H), 10.54 (s, 1H, NH). ${ }^{13} \mathrm{C}$ NMR (100 MHz, DMSO-d $\left.{ }_{6}\right)$ $\delta /$ ppm: 178.5, 175.3, 152.3, 148.0, 146.3, 136.2, 135.9, 130.9, 125.3, 124.2, 115.0, 108.8, 80.6, 38.9, 31.1. Anal. calcd for $\mathrm{C}_{17^{-}}$ $\mathrm{H}_{13} \mathrm{ClN}_{2} \mathrm{O}_{2} \mathrm{~S}, \% \mathrm{C}, 59.21 ; \mathrm{H}, 3.80 ; \mathrm{N}, 8.12$. Found, \%: C, 59.20; H, 3.78; N, 8.11.

5-Methyl-3' -phenylspiro[indoline-3, $\mathbf{2}^{\prime}$-thiazolidine]-2, $\mathbf{4}^{\prime}$ dione (4n). $\mathrm{Mp}>300{ }^{\circ} \mathrm{C}(\mathrm{MeOH}) .{ }^{1} \mathrm{H} \mathrm{NMR}\left(300 \mathrm{MHz}, \mathrm{DMSO}_{6}\right)$

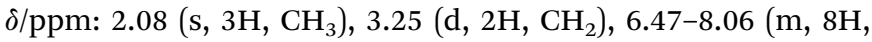
$\mathrm{Ar}-\mathrm{H}), 10.94$ (s, 1H, NH). ${ }^{13} \mathrm{C}$ NMR (100 MHz, DMSO-d 6 ) $\delta / \mathrm{ppm}$ : $180.0,170.8,157.0,154.0,146.8,143.6,125.8,121.1,118.3$, 117.8, 114.9, 108.7, 102.9, 71.8, 29.2. Anal. calcd for $\mathrm{C}_{17} \mathrm{H}_{14} \mathrm{~N}_{2} \mathrm{O}_{2} \mathrm{~S}$, \% C, 65.79; H, 4.55; N, 9.03. Found, \%: C, 65.75; $\mathrm{H}, 4.54$; N, 9.02.

$3^{\prime}$-(4-Methyl)-5-methylspiro[3H-indole-3,2' -thiazolidine]-2,4' (1H)-dione (4o). Mp 187-189 ${ }^{\circ} \mathrm{C}(\mathrm{MeOH}) .{ }^{1} \mathrm{H}$ NMR $(300 \mathrm{MHz}$, DMSO-d ${ }_{6}$ ) $\delta /$ ppm: $1.68\left(\mathrm{~s}, 3 \mathrm{H}, \mathrm{CH}_{3}\right), 2.48\left(\mathrm{~s}, 3 \mathrm{H}, \mathrm{CH}_{3}\right), 3.76$ (d, $\left.2 \mathrm{H}, \mathrm{CH}_{2}\right), 6.56-7.41(\mathrm{~m}, 7 \mathrm{H}, \mathrm{Ar}-\mathrm{H}), 11.08$ (s, 1H, NH). ${ }^{13} \mathrm{C} \mathrm{NMR}$ (100 MHz, DMSO-d 6 ) $\delta / \mathrm{ppm}: 177.4,165.9,152.4,150.4,148.4$, 141.7, 134.1, 133.0, 130.0, 124.8, 124.2, 121.6, 117.3, 116.6, 71.7, 36.5, 31.0. Anal. calcd for $\mathrm{C}_{18} \mathrm{H}_{16} \mathrm{~N}_{2} \mathrm{O}_{2} \mathrm{~S}, \% \mathrm{C}, 66.64 ; \mathrm{H}, 4.97 ; \mathrm{N}$, 8.64. Found, \%: C, 66.65; H, 4.82; N, 8.62.

$3^{\prime}$-(4-Fluorophenyl)-5-methylspiro[3H-indole-3, $2^{\prime}$-thiazolidine]-2,4'-(1H)-dione (4p). Mp 190-192 ${ }^{\circ} \mathrm{C}(\mathrm{MeOH}) .{ }^{1} \mathrm{H}$ NMR (300 MHz, DMSO-d ${ }_{6}$ ) $/$ ppm: $1.68\left(\mathrm{~s}, 3 \mathrm{H}, \mathrm{CH}_{3}\right), 2.68\left(\mathrm{~d}, 2 \mathrm{H}, \mathrm{CH}_{2}\right.$ ), 6.71-7.28 (m, 7H, ArH), 11.66 (s, 1H, NH). ${ }^{13} \mathrm{C}$ NMR (100 MHz, DMSO-d ${ }_{6}$ ) $\delta / \mathrm{ppm}: 20.9,24.6,32.6,73.1,116.08-140.34,150.8$, 167.2, 170.5, 118.02, 63.05. Anal. calcd for $\mathrm{C}_{17} \mathrm{H}_{13} \mathrm{FN}_{2} \mathrm{O}_{2} \mathrm{~S}, \% \mathrm{C}$, 62.18; H, 3.99; N, 8.53. Found, \%: C, 62.15; H, 3.88; N, 8.52.

3'-(2,3-Dihydro-1,5-dimethyl-3-oxo-2-phenyl-1H-pyrazol-4-yl)spiro[3H-indole-3, $2^{\prime}$-thiazolidine $]-2,4^{\prime}-(1 H)$ dione $(4 q) . \quad M p$ $320{ }^{\circ} \mathrm{C}(\mathrm{MeOH}) .{ }^{1} \mathrm{H}$ NMR (300 MHz, DMSO-d ${ }_{6}$ ) $\delta / \mathrm{ppm}: 2.50(\mathrm{~s}$, $\left.3 \mathrm{H}, \mathrm{CH}_{3}\right), 3.41\left(\mathrm{~s}, 3 \mathrm{H}, \mathrm{N}-\mathrm{CH}_{3}\right), 4.05\left(\mathrm{~d}, 2 \mathrm{H}, \mathrm{CH}_{2}\right), 6.70-8.12(\mathrm{~m}$, 9H, Ar-H), 10.63 (s, 1H, NH). ${ }^{13} \mathrm{C}$ NMR (100 MHz, DMSO-d 6 ) $\delta /$ ppm: 175.8, 173.8, 165.6, 155.8, 148.4, 144.3, 143.8, 133.2, 131.7, $121.9,121.0,115,9,108.8,72.4,29.6,22.0,15.5$. Anal. calcd for
$\mathrm{C}_{21} \mathrm{H}_{18} \mathrm{~N}_{4} \mathrm{O}_{3} \mathrm{~S} ; \% \mathrm{C}, 62.05 ; \mathrm{H}, 4.46 ; \mathrm{N}, 13.78$. Found \% C, 62.09; $\mathrm{H}, 4.45 ; \mathrm{N}, 13.79$.

5-Bromo-3' -(2,3-dihydro-1,5-dimethyl-3-oxo-2-phenyl-1H-pyrazol-4-yl)-spiro[3H-indole-3, $2^{\prime}$-thiazolidine]-2, $4^{\prime}-(1 H)$ dione $(4 \mathrm{r})$. Mp $333{ }^{\circ} \mathrm{C}(\mathrm{MeOH}) .{ }^{1} \mathrm{H}$ NMR (300 MHz, DMSO-d ${ }_{6}$ ) $\delta /$ ppm: 2.50 (s, 3H, $\mathrm{CH}_{3}$ ), 3.04 (s, 3H, N- $\mathrm{CH}_{3}$ ), 3.99 (d, 2H, $\mathrm{CH}_{2}$ ), 6.76-7.79 (m, 8H, Ar-H), 10.93 (s, 1H, NH). ${ }^{13} \mathrm{C}$ NMR (100 MHz, DMSO-d 6 ) $\delta /$ ppm: 178.2, 173.7, 169.9, 163.8, 162.3, 159.4, 157.1, 154.7, 148.5, 146.8, 131.1, 129.8, 128.3, 126.6, 124.3, 123.2, 70.1, 37.4, 17.0, 16.7. Anal. calcd for $\mathrm{C}_{21} \mathrm{H}_{17} \mathrm{BrN}_{4} \mathrm{O}_{3} \mathrm{~S} ; \% \mathrm{C}, 51.97 ; \mathrm{H}$, $3.53 ; \mathrm{N}, 11.54$. Found \% C, 51.89; H, 3.56; N, 11.59 .

5-Methyl-3'-(2,3-dihydro-1,5-dimethyl-3-oxo-2-phenyl-1Hpyrazol-4-yl)-spiro[3H-indole-3, $2^{\prime}$-thiazolidine $]-2,4^{\prime}-(1 H)$ dione (4s). Mp 328-330 ${ }^{\circ} \mathrm{C}(\mathrm{MeOH}) .{ }^{1} \mathrm{H}$ NMR (300 MHz, DMSO-d 6 ) $\delta /$ ppm: 2.67 (s, 3H, $\left.\mathrm{CH}_{3}\right), 2.73$ (s, 3H, N- $\left.\mathrm{CH}_{3}\right), 4.44$ (d, 2H, $\mathrm{CH}_{2}$ ), 6.74-7.97 (m, 8H, Ar-H), 10.65 (s, 1H, NH). ${ }^{13} \mathrm{C}$ NMR (100 MHz, DMSO-d $\left.{ }_{6}\right) \delta / p p m: 177.7,173.6,165.4,161.7,157.8,152.0,149.3$, 132.2, 131.9, 129.8, 129.7, 129.2, 124.8, 116.0, 115.6, 97.9, 69.5, 49.0, 31.1, 18.1, 14.2. Anal. calcd for $\mathrm{C}_{22} \mathrm{H}_{20} \mathrm{~N}_{4} \mathrm{O}_{3} \mathrm{~S}$; \% C, 62.84; H, 4.79; N, 13.32. Found \% C, 62.85; H, 4.76; N, 13.39 .

$3^{\prime}$-(1H-Benzimidazol-2-yl)-spiro-[3H-indole-3,2' -thiazolidine]-2,4'-(1H)-dione (4t). Mp $250{ }^{\circ} \mathrm{C}(\mathrm{MeOH}) .{ }^{1} \mathrm{H}$ NMR (300 MHz, DMSO-d ${ }_{6}$ ) $\delta /$ ppm: 4.81 (d, 2H, $\left.\mathrm{CH}_{2}\right), 6.72-8.35(\mathrm{~m}, 8 \mathrm{H}, \mathrm{Ar}-$ $\mathrm{H}), 10.75$ (s, 1H, NH), 10.89 (s, 1H, NH). ${ }^{13} \mathrm{C}$ NMR (100 MHz, DMSO-d ${ }_{6}$ ) $\delta /$ ppm: 177.6, 167.6, 157.8, 146.6, 141.5, 137.6, 131.0, 129.5, 129.3, 128.4, 126.0, 120.9, 104.9, 72.9, 32.9. Anal. calcd for $\mathrm{C}_{17} \mathrm{H}_{12} \mathrm{~N}_{4} \mathrm{O}_{2} \mathrm{~S} ; \% \mathrm{C}, 60.70 ; \mathrm{H}, 3.60 ; \mathrm{N}, 16.66$. Found C, 60.71; H, $3.55 ; \mathrm{N}, 16.69$.

5-Chloro-3' -(1H-benzimidazol-2-yl)-spiro-[3H-indole-3, $\mathbf{2}^{\prime}$ thiazolidine]-2,4'-(1H)-dione (4u). Mp $265{ }^{\circ} \mathrm{C}(\mathrm{MeOH}) .{ }^{1} \mathrm{H}$ NMR (300 MHz, DMSO-d ${ }_{6}$ ) $/$ ppm: 3.38 (d, 1H, CH), 4.39 (d, 1H, CH), 6.72-7.78 (m, 7H, Ar-H), 10.12 (s, 1H, NH), 12.89 (s, 1H, NH). ${ }^{13} \mathrm{C}$ NMR (100 MHz, DMSO-d 6 ) $\delta /$ ppm: 171.4, 167.6, 150.9, 145.0, 139.2, 132.0, 130.2, 128.0, 127.2, 126.0, 123.8, 122.4, 118.0, 108.0, 65.3, 29.8. Anal. calcd for $\mathrm{C}_{17} \mathrm{H}_{11} \mathrm{ClN}_{4} \mathrm{O}_{2} \mathrm{~S} ; \% \mathrm{C}, 55.06 ; \mathrm{H}$, 2.99; N, 15.11. Found C, 55.01; H, 2.97; N, 15.09.

5-Methyl-3' -(1H-benzimidazol-2-yl)-spiro-[3H-indole-3, $\mathbf{2}^{\prime}$ thiazolidine]-2,4'-(1H)-dione (4v). Mp $240{ }^{\circ} \mathrm{C}(\mathrm{MeOH}) .{ }^{1} \mathrm{H}$ NMR

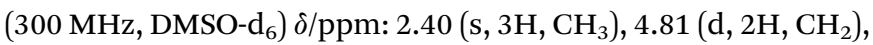
6.44-8.35 (m, 7H, ArH), 10.74 (s, 1H, NH), 10.98 (s, $1 \mathrm{H}, \mathrm{NH}) .{ }^{13} \mathrm{C}$ NMR (100 MHz, DMSO-d ${ }_{6}$ ) $\delta /$ ppm: 174.2, 166.2, 164.4, 164.1, $155.7,155.4$, 152.3, 150.5, 132.7, 128.4, 127.7, 124.7, 117.4, $116.5,115.3,105.4,77.5,35.7,30.9$. Anal. calcd for $\mathrm{C}_{18} \mathrm{H}_{14} \mathrm{~N}_{4} \mathrm{O}_{2} \mathrm{~S}$, \% C, 61.70; H, 4.03; N, 15.99. Found, \%: C, 61.65; H, 4.01; N, 15.92 .

$3^{\prime}$-(1,3-Benzothiazol-2-yl)-spiro-[3H-indole-3,2'-thiazolidine] 2,4'-(1H)-dione (4w). Mp $168{ }^{\circ} \mathrm{C}(\mathrm{MeOH}) .{ }^{1} \mathrm{H}$ NMR $(300 \mathrm{MHz}$, DMSO-d 6 ) $\delta /$ ppm: 4.41 (d, 1H, CH), 4.86 (d, 1H, CH), 6.97-7.65 $(\mathrm{m}, 8 \mathrm{H}, \mathrm{Ar}-\mathrm{H}), 10.95$ (s, 1H, NH). ${ }^{13} \mathrm{C}$ NMR (100 MHz, DMSO-d 6 ) $\delta / \mathrm{ppm}: 175.6,170.6,156.8,143.6,141.5,136.6,130.0,129.5$, $127.3,126.4,126.0,121.9,108.9,74.9,32.1$. Anal. calcd for $\mathrm{C}_{17} \mathrm{H}_{11} \mathrm{~N}_{3} \mathrm{O}_{2} \mathrm{~S}_{2} ; \mathrm{C}, 57.77 ; \mathrm{H}, 3.14 ; \mathrm{N}, 11.89$. Found C, 57.70; H, $3.13 ; \mathrm{N}, 11.85$.

5-Chloro-3' -(1,3-benzothiazol-2-yl)-spiro-[3H-indole-3,2' thiazolidine]-2,4'-(1H)-dione (4x). Mp $171{ }^{\circ} \mathrm{C}(\mathrm{MeOH}) .{ }^{1} \mathrm{H}$ NMR (300 MHz, DMSO-d ${ }_{6}$ ) $/$ ppm: 4.47 (d, 1H, CH), 4.84 (d, 1H, CH), 6.89-7.75 (m, 7H, Ar-H), 10.59 (s, 1H, NH). ${ }^{13} \mathrm{C}$ NMR (100 MHz, 
DMSO-d $)_{6}$ ) $/$ ppm: 175.5, 169.3, 159.2, 144.6, 142.2, 137.7, 136.9, 132.8, 129.0, 128.1, 127.0, 123.7, 122.6, 122.3, 107.7, 65.0, 25.7. Anal. calcd for $\mathrm{C}_{17} \mathrm{H}_{10} \mathrm{ClN}_{3} \mathrm{O}_{2} \mathrm{~S}_{2} ; \% \mathrm{C}, 52.64 ; \mathrm{H}, 2.60 ; \mathrm{N}, 10.83$. Found \% C, 52.70; H, 2.62; N, 10.86 .

5-Methyl-3' -(1,3-benzothiazol-2-yl)-spiro-[3H-indole-3, $\mathbf{2}^{\prime}$ thiazolidine]-2,4'-(1H)-dione (4y). Mp $163{ }^{\circ} \mathrm{C}(\mathrm{MeOH}) .{ }^{1} \mathrm{H}$ NMR (300 MHz, DMSO-d ${ }_{6}$ ) $/$ ppm: $2.24\left(\mathrm{~s}, 3 \mathrm{H}, \mathrm{CH}_{3}\right), 3.87$ (d, 1H, CH), 4.51 (d, 1H, CH), 7.06-7.66 (m, 7H, Ar-H), 8.30 (s, 1H, NH). ${ }^{13} \mathrm{C}$ NMR (100 MHz, DMSO-d ${ }_{6}$ ) $\delta /$ ppm: 178.4, 169.9, 160.6, 141.9, 140.7 , 134.7, 132.2, 131.4, 130.6, 129.5, 129.0, 127.7, 128.4, 123.7, 122.2, 66.0, 20.9. Anal. calcd for $\mathrm{C}_{18} \mathrm{H}_{13} \mathrm{~N}_{3} \mathrm{O}_{2} \mathrm{~S}_{2} ; \% \mathrm{C}$, 58.84; H, 3.57; N, 11.44. Found \% C, 58.76; H, 3.55; N, 11.42.

3'-(6-Chloro-1,3-benzothiazol-2-yl)-spiro-[3H-indole-3,2' thiazolidine]-2, $\mathbf{4}^{\prime}$-(1H)-dione (4z). Mp $170{ }^{\circ} \mathrm{C}(\mathrm{MeOH}) .{ }^{1} \mathrm{H}$ NMR (300 MHz, DMSO-d ${ }_{6}$ ) $/ \mathrm{ppm}: 3.43$ (d, 2H, $\mathrm{CH}_{2}$ ), 6.93-8.21 (m, $7 \mathrm{H}, \mathrm{Ar}-\mathrm{H}), 10.87$ (s, 1H, NH). ${ }^{13} \mathrm{C}$ NMR (100 MHz, DMSO-d 6 ) $\delta /$ ppm: 175.8, 171.7, 157.2, 154.2, 147.8, 143.1, 127.8, 125.1, 120.7, 118.2, 117.8, 112.1, 102.7, 70.0, 21.2. Anal. calcd for $\mathrm{C}_{17} \mathrm{H}_{10^{-}}$ $\mathrm{ClN}_{3} \mathrm{O}_{2} \mathrm{~S}_{2} ; \% \mathrm{C}, 52.64 ; \mathrm{H}, 2.60 ; \mathrm{N}, 10.83$. Found \% C, 52.70; H, $2.62 ; \mathrm{N}, 10.86$.

\section{Conclusions}

In this study, a nanoporous poly (ionic liquid) is proposed to facilitate the synthesis of the pharmaceutical spiro-4thiazolidinone library. In practice, two different methods were applied to study the effect of polymerization protocol on morphology and efficiency of prepared sonocatalyst. According to the obtained results, hydrothermal precipitation polymerization provided a higher degree of cross linking and as a result achieved more thermal stability, and porous structure (smaller pore size distribution) which are known as the key characteristic parameters in the catalysis field. On the other hand, the synergistic effect between US irradiation and magnetically separable catalyst play a vital role in the straightforward synthesis of spiro-4-thiazolidinones.

\section{Conflicts of interest}

There are no conflicts to declare.

\section{Acknowledgements}

The authors acknowledge a reviewer who provided helpful insights. The authors are grateful to the Islamic Azad University, Qom Branch, Qom, I. R. Iran for supporting this work.

\section{References}

1 R. Abraham, P. Periakaruppan, K. Mahendran and M. Ramanathan, Microb. Pathog., 2018, 114, 409-413.

2 S. Dadashpour and S. Emami, Eur. J. Med. Chem., 2018, 150, 9-29.

3 S. K. Siddiqui, V. J. SahayaSheela, S. Kolluru, G. N. Pandian, T. R. Santhoshkumar, V. M. Dan and C. V. Ramana, Bioorg. Med. Chem. Lett., 2020, 30, 127431.
4 S. Mishra, M. Kaur, S. Chander, S. Murugesan, L. Nim, D. S. Arora and P. Singh, Eur. J. Med. Chem., 2018, 155, 658-669.

5 P. S. S. Gupta, H. Rasool Bhat, S. Biswal and M. Kumar Rana, J. Mol. Liq., 2020, 114375.

6 Z. Bakherad, M. Safavi, A. Fassihi, H. Sadeghi-Aliabadi, M. Bakherad, H. Rastegar, J. B. Ghasemi, S. Sepehri, L. Saghaie and M. Mahdavi, Res. Chem. Intermed., 2019, 45, 2827-2854.

7 S. Holota, A. Kryshchishyn, H. Derkach, Y. Trufin, I. Demchuk, A. Gzella, P. Grellier and R. Lesyk, Bioorg. Chem., 2019, 86, 126-136.

8 A. Deep, B. Narasimhan, S. M. Lim, K. Ramasamy, R. K. Mishra and V. Mani, RSC Adv., 2016, 6, 109485-109494.

9 M. Mushtaque, F. Avecilla, Z. B. Hafeez and M. M. A. Rizvi, J. Heterocycl. Chem., 2019, 56, 1794-1805.

10 A. Preetam and M. Nath, Tetrahedron Lett., 2016, 57, 15021506.

11 R. Singh, A. Singh and D. Bhardwaj, ChemistrySelect, 2019, 4, 9600-9607.

12 D. P. Anekal and J. S. Biradar, Arabian J. Chem., 2017, 10, S2098-S2105.

13 M. P. Thakare, P. Kumar, N. Kumar and S. K. Pandey, Tetrahedron Lett., 2014, 55, 2463-2466.

14 Y. Jiang, Y. Zhang, L. Ding, J. A. De, L. Cruz, B. Wang, X. Feng, Z. Chen, Z. Mao and X. Sui, Carbohydr. Polym., 2019, 223, 115079.

15 H. Gao, Chin. Chem. Lett., 2019, 30, 1996-2002.

16 Z. Dastjerdi, E. D. Cranston, R. Berry, C. Fraschini and M. A. Dube, Macromol. React. Eng., 2019, 13, 1800050.

17 W. V. Smith and R. H. Ewart, J. Chem. Phys., 1948, 16, 592599.

18 J. Chen, C. Zhao, H. Huang, M. Wang and X. Ge, Polymer, 2016, 83, 214-222.

19 C. G. Gutierrez, G. Cáceres Montenegro, R. J. Minari, J. R. Vega and L. M. Gugliotta, Macromol. React. Eng., 2019, 13, 1900007.

20 H. Yang, H. Kang, B. Wang and R. Liu, Colloids Surf., A, 2020, 587, 124315.

21 R. Zeng, Y. Chen, L. Zhang and J. Tan, Polym. Chem., 2020, 11, 4591-4603.

22 J. Tan, Y. Bai, X. Zhang, C. Huang and D. Liu, Macromol. Rapid Commun., 2016, 37, 1434-1440.

23 A. Eftekhari and T. Saito, Eur. Polym. J., 2017, 90, 245-272.

24 J. Yuan, D. Mecerreyes and M. Antonietti, Prog. Polym. Sci., 2013, 38, 1009-1036.

25 Z. Wang, Y. Si, C. Zhao, D. Yu, W. Wang and G. Sun, ACS Appl. Mater. Interfaces, 2019, 11, 27200-27209.

26 P. Pillai and A. Mandal, J. Mol. Liq., 2020, 302, 112553.

27 B. Lin, W. Yuan, F. Xu, Q. Chen, H. Zhu, X. Li, N. Yuan, F. Chu and J. Ding, Appl. Surf. Sci., 2018, 455, 295-301.

28 G. Yang, Q. Huang, H. Huang, J. Chen, Y. Lei, F. Deng, M. Liu, Y. Wen, X. Zhang and Y. Wei, J. Mol. Liq., 2020, 300, 112267.

29 J. S. Lee, K. Sakaushi, M. Antonietti and J. Yuan, RSC Adv., 2015, 5, 85517-85522. 
30 A. Dani, V. Crocellà, L. Maddalena, C. Barolo, S. Bordiga and E. Groppo, J. Phys. Chem. C, 2016, 120, 1683-1692.

31 S. Sadjadi and F. Koohestani, J. Mol. Liq., 2020, 301, 112414. 32 M. Yin, Q. Zhao, J. Wu, K. Seefeldt and J. Yuan, ACS Nano, 2018, 12, 12551-12557.

33 S. Lopez-Orozco, A. Inayat, A. Schwab and T. Selvam, Adv. Mater., 2011, 23, 2602-2615.

34 J. Pérez-Ramírez, D. Verboekend and A. Bonilla, Adv. Funct. Mater., 2009, 19, 3972-3979.

35 S. Zheng, T. Wu, C. Chou, A. Fuhr, P. Feng and X. Bu, J. Am. Chem. Soc., 2012, 134, 4517-4520.

36 Y. Liu, J. F. Eubank, A. J. Cairns, J. Eckert, V. Ch. Kravtsov and R. Luebke, Angew. Chem., Int. Ed. Engl., 2007, 119, 3342-3347.

37 Z. Ren, Y. Lyu, X. Song, Y. Liu, Z. Jiang, R. Lin and Y. Ding, Adv. Mater., 2019, 31, 1904976.

38 W. Hui, X. M. He, X. Y. Xu, Y. M. Chen, Y. Zhou, Z. M. Li, L. Zhang and D. J. Tao, J. CO $\mathrm{C}_{2}$ Util., 2020, 36, 169-176.

39 Y. Xie, J. Lin, H. Lin, Y. Jiang, J. Liang, H. Wang, S. Tu and J. Li, J. Hazard. Mater., 2020, 392, 122496.

40 X. Wang, S. Ma, B. Chen, J. Zhang, Y. Zhang and G. Gao, Green Energy Environ., 2020, 5, 138-146.

41 S. Y. Zhang, Q. Zhuang, M. Zhang, H. Wang, Z. Gao, J. K. Sun and J. Yuan, Chem. Soc. Rev., 2020, 49, 1726-1755.
42 J. Safaei Ghomi and S. Zahedi, Ultrason. Sonochem., 2017, 34, 916-923.

43 J. Safaei-Ghomi, R. Masoomi, M. Hamadanian and S. Naseh, New J. Chem., 2016, 40, 3289-3299.

44 J. Safaei-Ghomi, M. Tavazo and G. H. Mahdavinia, Ultrason. Sonochem., 2018, 40, 230-237.

45 J. Safaei-Ghomi, Z. Akbarzadeh and R. Teymuri, Res. Chem. Intermed., 2019, 45, 3425-3439.

46 Z. Akbarzadeh and J. Safaei-Ghomi, Green Chem. Lett. Rev., 2020, 13, 141-154.

$47 \mathrm{~V}$. Thangaraj, A. Bhaskarapillai and S. Velmurugan, J. Hazard. Mater., 2020, 384, 121481.

48 D. Kaminskyy, D. Khyluk, O. Vasylenko, L. Zaprutko and R. Lesyk, Sci. Pharm., 2011, 79, 763-777.

49 A. Dandia, R. Singh, S. Bhaskaran and S. D. Samant, Green Chem., 2011, 13, 1852-1859.

50 M. M. Li, C. S. Duan, Y. Q. Yu and D. Z. Xu, Dyes Pigm., 2018, 150, 202-206.

51 R. Mohammadi, S. Esmati, M. G. Nazari and R. Teimory Mofrad, J. Mol. Liq., 2019, 275, 523-534.

52 M. A. Ghasemzadeh and Z. Elyasi, Iran. J. Catal., 2017, 7, 7583. 